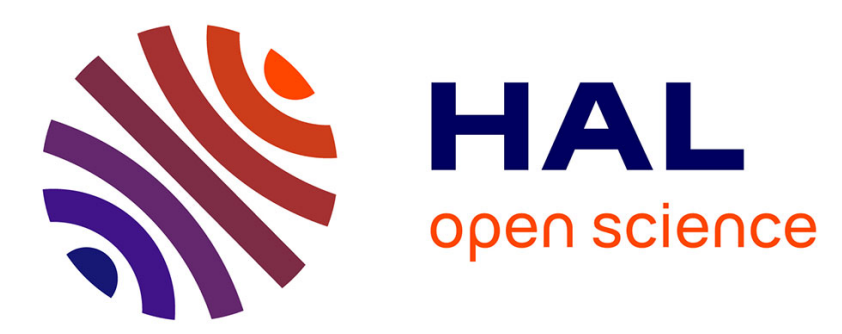

\title{
A study on the effects of an explosion in the Pantheon of Rome
}

Filippo Masi, Ioannis Stefanou, P Vannucci

\section{To cite this version:}

Filippo Masi, Ioannis Stefanou, P Vannucci. A study on the effects of an explosion in the Pantheon of Rome. Engineering Structures, 2018, 164, pp.259-273. 10.1016/j.engstruct.2018.02.082 . hal01493006v2

\section{HAL Id: hal-01493006 \\ https://hal.science/hal-01493006v2}

Submitted on 19 Dec 2017

HAL is a multi-disciplinary open access archive for the deposit and dissemination of scientific research documents, whether they are published or not. The documents may come from teaching and research institutions in France or abroad, or from public or private research centers.
L'archive ouverte pluridisciplinaire HAL, est destinée au dépôt et à la diffusion de documents scientifiques de niveau recherche, publiés ou non, émanant des établissements d'enseignement et de recherche français ou étrangers, des laboratoires publics ou privés.

\section{(c)(1)}

Distributed under a Creative Commons Attribution| 4.0 International License 


\title{
A study on the effects of an explosion in the Pantheon of Rome
}

\author{
F. Masi ${ }^{1}$, I. Stefanou ${ }^{1}$, and P. Vannucci*2 \\ ${ }^{1}$ Laboratoire Navier - UMR8205, CNRS, ENPC \& IFSTTAR. \\ Université Paris-Est, Marne La Vallée (F) \\ ${ }^{2}$ LMV, Laboratoire de Mathématiques de Versailles - UMR8100 CNRS \& UVSQ. \\ University Paris-Saclay, Versailles (F)
}

December 19, 2017

\begin{abstract}
The response of an emblematic monumental structure, the Pantheon in Rome, to an internal blast is addressed. The analysis is a coupled solid-fluid numerical simulation done using JWL equation for the simulation of the blast event and considering the pre-existent cracks in the dome as well as the material nonlinearities of low-tensile strength concrete aggregates. We identify two main phenomena; a focalization of shock waves inside dome-vaulted like structures due to their tendency to concentrate the blast energy and the role played by the pre-existent cracks in the evolution of the structural damage
\end{abstract}

Key words: blast actions; CEL approach; JWL; fast-dynamics; monumental structures; brittle cracking; Pantheon of Rome.

\section{Introduction}

We propose in this paper a study on the structural effects of an explosion in the Pantheon of Rome. Highly representative monuments are unfortunately too often the objective of violences and iconoclastic destructions. Well-known examples are the Parthenon in 1687, the Cathedral of Reims in 1914, the Buddha statues of Bamyan in 2001 and the more recent destructions at Palmyra in 2015 and 2016.

Research on the effects of an explosion on monumental architectures are hence interesting for assessing the potential effects of a blast onto a monument structure and also for helping in the design of reinforcements or any other possible passive protection device.

This domain is still almost unexplored; in fact, the most part of papers concerning the effects of an explosion on a civil structure regard modern reinforced concrete or steel

${ }^{*}$ Corresponding author: Paolo VAnnuCCI. LMV, 45 Avenue des Etats-Unis. 78035 Versailles, France E-mail: paolo.vannucci@uvsq.fr 
structures with simple geometries, normally squared buildings, [Remennikov, 2003], [Ngo et al., 2007], [Koccaz et al., 2008], [Draganic and Sigmund, 2012].

This is not the case of monumental structures that have often a complex geometry, sometimes very articulated, which renders the assessment of the blast loads strongly case dependent and affects the type of simulation. This point is tackled in Sect. 3, where a short account of the state of the art for what concerns the simulation of blast loads is given and, on its base, the choice of the method used for the case of Pantheon is justified.

On the other hand, monumental structures are either masonry-like or timber structures, or both of them at the same time. In particular, monuments constituted by masonry-like materials have a structural response strongly affected by the no-tension behavior of the material. This is a key point, considered in Sect. 4.

A particular attention must hence be paid to the procedure to be used for numerical simulations, that must account, on one hand, for the hypervelocity of the phenomenon and, on the other hand, for the peculiar constitutive law of the material, that must be able to describe the non-linear phenomenon of damage, i.e. of cracks propagating into the body of the structure as a consequence of the blast actions. Considerations about the procedure used for the numerical simulations are given in Sect. 5 and the results are presented in Sect. 6 .

But let us start by briefly introducing, in Sect. 2, the object of this study, the Pantheon of Rome.

\section{The Pantheon of Rome}

The Pantheon of Rome, one of the most admired and studied monuments ever, was built upon the rests of previous temples by the Emperor Hadrian, since A.D. 118 to about 128, or later, perhaps until 140, under Emperor Antoninus Pius, and probably it is the joint work of Hadrian and of the Nabatean great architect Apollodorus of Damascus (see [Marder and Jones, 2015]).

The main body of the Pantheon, the so-called Rotonda, is composed by a cylinder whose inscribed sphere is coincident, for its upper part, with the dome, while its bottom touches the ground, Fig. 2. The coffering is sculpted in the intrados of the dome offering a high aesthetic value, but also reducing the dome's weight.

With a diameter of $43.30 \mathrm{~m}$, according to the measurements of de Fine Licht, [K. de Fine Licht, 1968], [Mark, 1990], or of 150 Roman feet, i.e. 44.55 m, according to WilsonJones, [Wilson-Jones, 2000], [Como, 2013], the Pantheon's dome is, still today, the largest dome in the world, apart the modern realizations in reinforced concrete. In fact, it is larger than the dome of Saint Peter in Vatican, whose diameter is $42 \mathrm{~m}$, and also of the octagonal dome of F. Brunelleschi, in Santa Maria del Fiore at Florence, whose base is circumscribed to a circle of $41.57 \mathrm{~m}$ diameter, [Cowan, 1977]. However, unlike these two famous domes, and also of other ones, made by bricks, the Pantheon's one is made of concrete, a technique already mastered by Apollodorus in other previous works (e.g. the vault of the Great Hall in the Trajan's markets in Rome, see [Perucchio and Brune, 2008], [Perucchio and Brune, 2009]). 

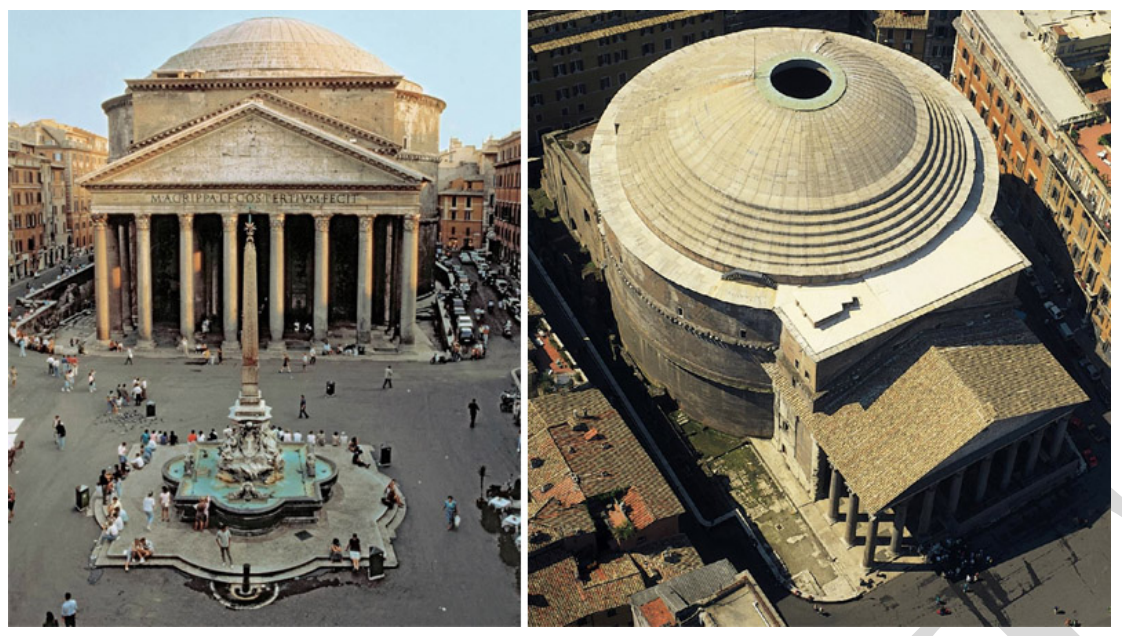

Figure 1: The Pantheon of Rome (from [Pulvirenti, 2014]).
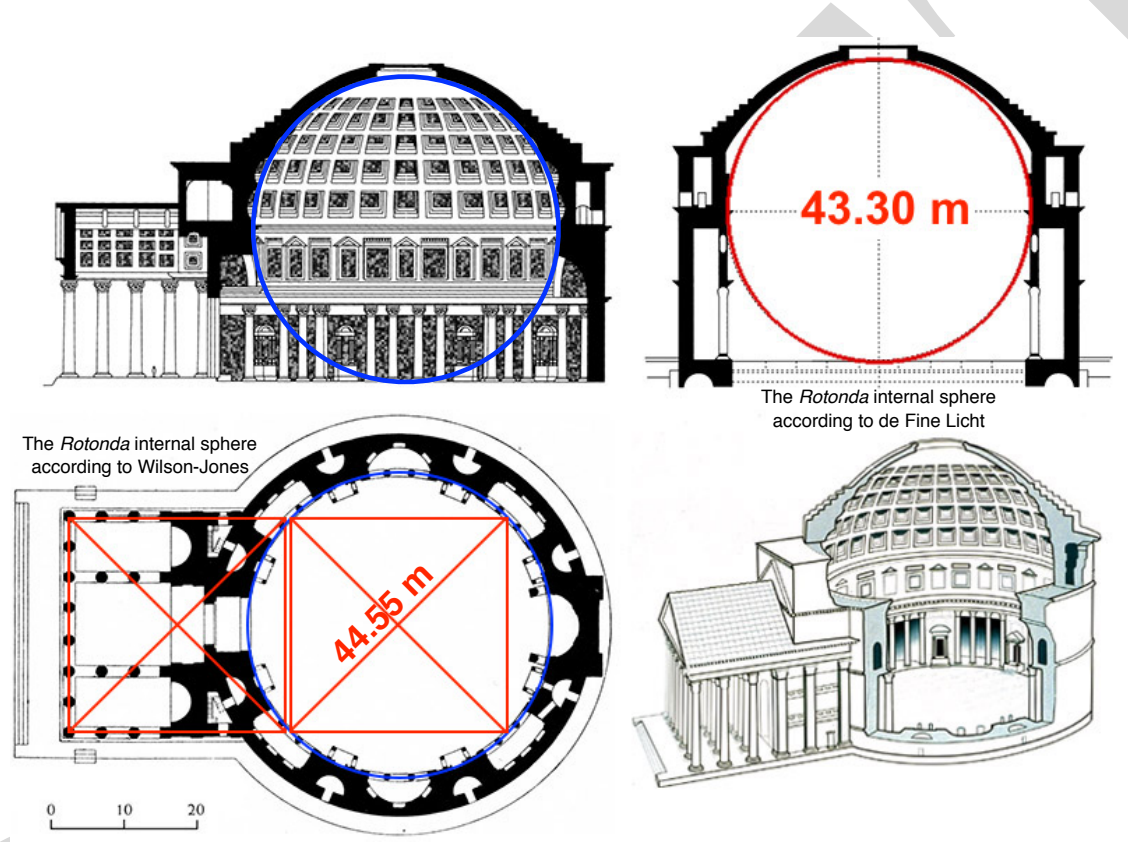

Figure 2: Scheme and dimensions of the Pantheon (from [Pulvirenti, 2014]).

If the intrados of the dome is sculpted by a coffering, the external lowest part of the dome is modeled by stepped rings, whose function has been the object of different investigations, see Fig. 2. In an early application of finite element analysis to Roman structures, Mark and Hutchinson [Mark and Hutchinson, 1986], [Mark, 1990] used a simplified two-dimensional model of the Rotonda, exploiting the axial symmetry of the structure. According to this study, and contrary to what commonly thought, the step-rings do not contrast the hoop tension in the lowest part of the dome, because actually the dome is spread of cracks that have an almost meridional direction and stop at a latitude of approximately $57^{\circ}$, where the hoop stress begins to be compressive.

The distribution of these cracks, Fig. 3, was detailed in 1934 by A. Terenzio, the Superintendent of the Monuments of Latium, who had carried on a series of inspections on the dome of the Rotonda after that some fragments had fallen down, [Terenzio, 1934]. 
We cannot establish here what is the true origin of these cracks, but certainly they are to be modeled to have a more realistic response of the structure to gravity and blast loads. In fact, on one hand, the cracks undoubtedly change the stress regime of the Rotonda, on the other hand, they considerably affect the response of the structure to a blast by a special local mechanism, as we will see in Sect. 6.2.

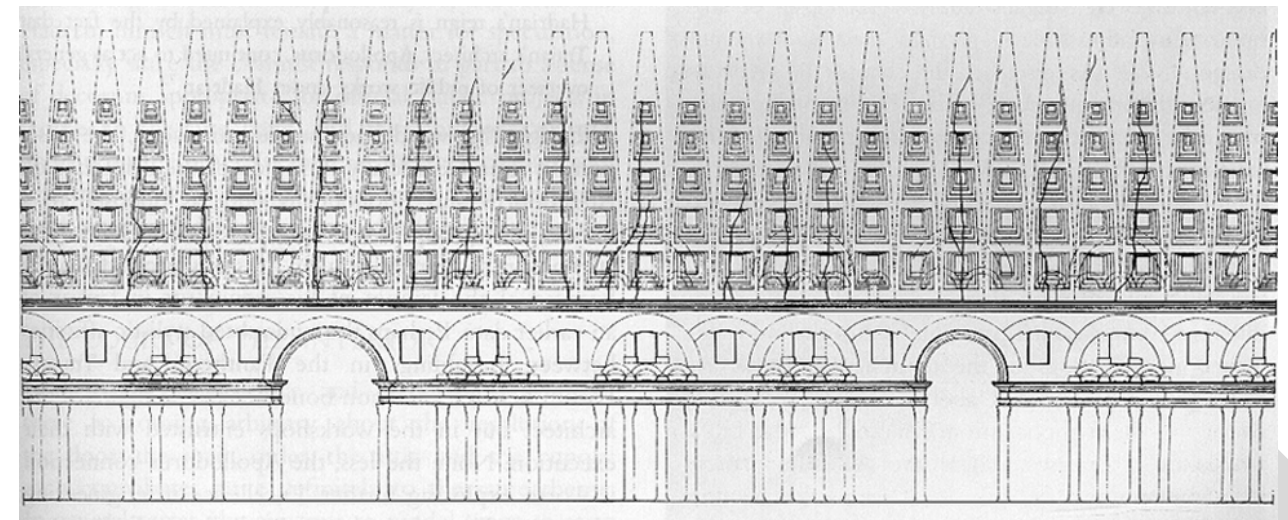

Figure 3: Meridional cracks in the Rotonda's dome (after [Terenzio, 1934]).

\section{Modeling the blast actions}

An explosion is an extremely rapid and exothermal chemical reaction, which lasts just few milliseconds. During detonation, hot gases, pertaining to the chemical process, expand quickly and, for the hot temperatures produced almost instantaneously, the air around the blast expands. The result is a blast shock wave, characterized by a thin zone of air propagating spherically much faster than the sound speed, through which pressure is discontinuous. We describe below this phenomenon, more details can be found in [Vannucci et al., 2017a].

Let us first introduce some quantities used in the following:

- $W$ : explosive mass.

- $R=\|q-o\|:$ distance of a point $q$ from the detonation point $o$.

- $P_{o}$ : ambient pressure.

- $P_{s}$ : overpressure due to the blast; it is the pressure in the air relative to $P_{o}$.

- $P_{r}$ : reflected overpressure, i.e., the pressure, relative to $P_{o}$, acting at a point $q$ of a solid surface when hit orthogonally by a shock-wave.

- $t_{A}$ : arrival time, i.e., the instant at which the shock-wave peak arrives at $q$.

- $t_{o}$ : positive phase duration, defined below.

- $t_{o-}$ : negative phase duration, defined below.

Figure 4 represents an ideal profile of the overpressure $P_{s}(q, t)$ produced by a blast. When the shock wave arrives at $q$, after $t_{A}$, the pressure instantaneously increases from the ambient pressure $P_{o}$ to a peak for $P_{s}$ : a strong discontinuity, indeed. 
For $t>t_{A}$ the overpressure decreases exponentially until time $t_{A}+t_{o}$, when $P_{s}=P_{o}$, which marks the end of the so-called positive phase. After $t_{A}+t_{o}$, we have the negative phase: the pressure decreases with respect to $P_{o}$ and comes back to $P_{o}$ after $t_{o-}>t_{o}$. During the negative phase the decrement of the pressure is in modulus much lower than the peak pressure of the positive phase. Consequently, the negative phase can be neglected for structural analyses, though it can be important in some special cases, due to its duration, always much longer than the positive phase. Such a behavior is idealized: perturbations can occur, due to different circumstances.

The shock wave is the main mechanical effect of a blast on a structure, but not the only one: hot gases, expanding, produce the so-called dynamic pressure, least in value with respect to the shock wave and propagating at a lesser speed, while the impinging shock wave can be reflected by solid surfaces and acts again on other surfaces as reflected shock wave.

The overpressure $P_{s}$ at a point $q$ decreases with increasing time $t$ and distance $R$. Generally, the time rate decrement is much greater than the space rate one: the blast overpressure is like a localized pressure wave propagating at high speed and decreasing intensity in the distance.

$P_{r}$ is the pressure acting on a surface impinged by the incident overpressure $P_{s}$. The peak of $P_{r}$ is normally much greater than the one of $P_{s}$, measured at the same point and assuming the absence of any surface.

The simulation of a blast can be conducted by using different approaches. Here we refer to three phenomenological approaches: JWL, CONWEP, and TM5-1300 models.

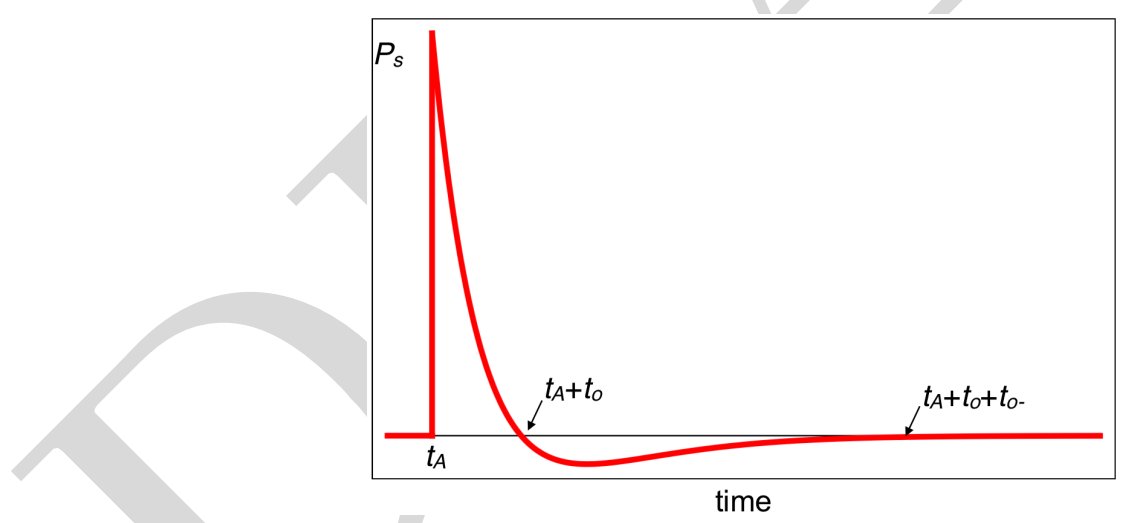

Figure 4: Scheme of the time variation of the pressure due to a blast.

JWL stands for Jones, Wilkins and Lee, the authors of this model, [Jones and Miller, 1948], [Wilkins, 1964], [Lee et al., 1968]. The JWL model is physically based: the laws of thermodynamics are used to recover a phenomenological description of a chemical blast. It allows a detailed description of a blast phenomenon, including the propagation of the shock-wave in a medium, e.g. air, its reflection on solid surfaces and the expansion of the hot gases, i.e. the dynamic pressure.

The JWL model gives the overpressure $P_{s}$ as function of different parameters:

$$
P_{s}=A\left(1-\frac{\omega \rho}{R_{1} \rho_{0}}\right) \exp \left(-R_{1} \frac{\rho_{0}}{\rho}\right)+B\left(1-\frac{\omega \rho}{R_{2} \rho_{0}}\right) \exp \left(-R_{2} \frac{\rho_{0}}{\rho}\right)+\omega \rho E_{m}
$$


$A, B, R_{1}, R_{2}$ and $\omega$ are parameters depending upon the explosive type, along with $\rho_{0}$, its density, while $\rho$ is the density of the detonation products and $E_{m}$ is the internal energy per unit mass. The detonation velocity $v_{D}$ and the Chapman-Jouguet pressure $p_{c j}$ need to be specified too. All their values are selected to fit experimental results on the cylinder expansion test (see Table 1).

Table 1: Physical parameters for the state equations for explosive, after [Lee et al., 1973].

\begin{tabular}{cccccccc}
\hline $\begin{array}{c}\rho_{0} \\
{\left[\mathrm{~kg} / \mathrm{m}^{3}\right]}\end{array}$ & $\begin{array}{c}v_{D} \\
{[\mathrm{~m} / \mathrm{s}]}\end{array}$ & $\begin{array}{c}A \\
{[\mathrm{MPa}]}\end{array}$ & $\begin{array}{c}B \\
{[\mathrm{MPa}]}\end{array}$ & $\omega$ & $R_{1}$ & $R_{2}$ & $\begin{array}{c}E_{m} \\
{[\mathrm{~kJ} / \mathrm{kg}]}\end{array}$ \\
\hline 1630 & 6930 & 373770 & 3747.1 & 0.35 & 4.15 & 0.9 & 3680 \\
\hline
\end{tabular}

Though the detailed modeling of a blast, JWL model needs of discretizing, finely, the charge and the fluid domain, that can be very large, besides the structure if a coupled structural analysis is to be done.

Multi-physics transient problems, with a strong fluid-structure coupling, lead to numerical simulations that can be heavy. Empirical methods are often used for their reduced computational costs. The two most commonly used empirical models rest upon different but related studies of the U.S. Army Corps of Engineers (USACE): the document [USACE, 1986] and the Technical Manual TM5-1300 [USACE, 1990]. They contain the model CONWEP, completed by successive documents [USACE, 2008]. The Joint Research Center of the European Union has produced in 2013 a Technical Report [Karlos and Solomos, 2013] substantially referring to these two last USACE documents and to another Technical Report of the U.S. Army [Kingery and Bulmash, 1984].

Such empirical models are less precise in predictions than JWL, especially because they neglect reflected waves, which may have, in contrast, prominent effects, especially for internal blasts. Depending upon geometry, the concentration of the reflected waves can give rise to local effects that can be greater than the original shock wave. In the case of vaulted structures limited laterally by walls, a localized shock wave produced by the reflected waves can hit the vault with an overpressure far greater than that produced directly by the original impinging shock wave [Vannucci et al., 2017a], [Masi, 2017].

The case of the Rotonda is hence particularly interesting: by its geometry, focalizing effects can happen and be determinant. That is why we have chosen to study the problem of a blast inside the Pantheon using the JWL model, that allows for modeling completely the explosion. This needs the discretization not only of the structure, to perform the coupled structural analysis, but also of the air volume inside and partly outside the Pantheon. This is a step forward with respect to a previous study of the authors, where the CONWEP model was used, [Vannucci et al., 2017b]. Finally, we have a very huge numerical model, needing a considerable computational effort; this aspect is detailed in Sect. 5 .

\section{Modeling the material behavior}

The Pantheon is made by different materials: bricks, mortar and concrete, for the cylindrical part of the Rotonda, granite for the columns inside and concrete for the dome. The 
cylindrical part, whose thickness varies from $\sim 2.4 \mathrm{~m}$ to $\sim 6 \mathrm{~m}$, is actually composed also by pillars and arches, having a structural role and merged in the wall. Concerning the dome, it is more correct to say that it is composed of concretes, because the Romans used different types of concrete, from the heaviest one in the lower part, whose thickness is $\sim 5.9 \mathrm{~m}$, to the lightest one in the upper part of the dome, where the thickness decreases to $\sim 1.5 \mathrm{~m}$, see Fig. 5 .

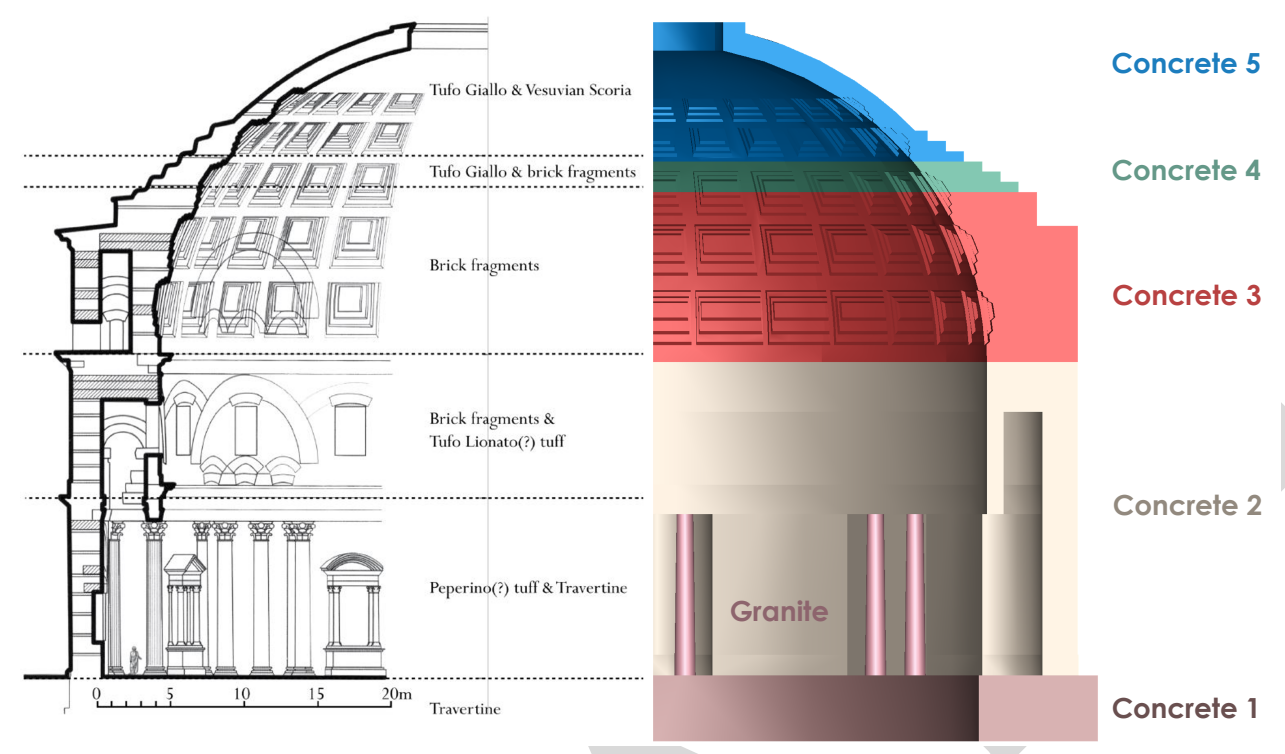

Figure 5: Materials composing the Rotonda as in [Lancaster, 2005] (left) and as in Tab. 3.

\subsection{Characterisation of the materials}

In this study, we have used the same mechanical model for the constitutive law of the concretes composing the dome or the foundations, the masonry of the cylindrical part and the granite of the columns. We precise that we have modeled the masonry as an equivalent concrete, as it is almost impossible, for such a large structure, to model precisely the actual disposition of the bricks composing the pillars and numerous arches included in the masonry of the Rotonda, see Fig. 5.

The materials are assumed to be linearly elastic in compression. It is commonly considered that in monumental structures compression stresses are very low, usually an order of magnitude below the compressive strength of the material, cf. [Heyman, 1995, Stefanou et al., 2015], so that there is no possibility of crushing. However, in the present study where the main actions are produced by a blast, this assumption may be questionable: high compressive stresses produced by the shock wave cannot be excluded a priori in some parts of the structure. That is why in our approach the consistency of the subsequent calculations is checked by monitoring that the compressive stresses do not exceed the compressive strength, assumed to be, for all the concretes, equal to $\sim 5 \mathrm{MPa}$, according to the experimental results by [Samuelli-Ferretti, 1996] and [Giavarini et al., 2006] and the models proposed in [Brune, 2010] and [Ivancic et al., 2014]. The verification is given in the Appendix. 
Masonry and concrete show a low strength to tensile stresses, so small that often they are modeled as no-tension materials. In our study, a small, but not null, tensile strength $f_{t}$ is considered for the material. When $f_{t}$ is exceeded, damage occurs and the following tensile softening is characterised, as proposed in [Hillerborg et al., 1976], in terms of the fracture energy $G_{f}$, i.e., the energy required to open a unit area of crack in Mode I.

Different material characteristics must be determined in order to adequately define their mechanical response: the density $\rho$, the Young's modulus $E$, the Poisson's ratio $\nu$, the tensile strength $f_{t}$, the fracture energy $G_{f}$ and the softening behavior.

We have considered five zones for the materials of the Rotonda, corresponding to those indicated in Fig. 5: foundations, brick-faced concrete of the cylindrical wall, lower, intermediate and upper zone of the dome. In addition, we have considered apart the material of the columns in the interior of the Rotonda, made of granite.

The concrete densities have been fixed upon the indications given in [Mark and Hutchinson, 1986]. About the other quantities, the choice is much more problematic. Though we know today rather well the behavior of light concretes, according to historians and researchers in mechanics of ancient monuments, the physical properties of concretes and mortars of the past have quite different characteristics. Moreover, the data that can be found in the literature about ancient concretes are often quite different and most of all fragmentary. The only reliable data about the Pantheon were the densities. Therefore we needed a rationale linking in some way the other material parameters to densities in such a way that, starting from few known data, the other ones could be determined.

For all the concretes, we have put $\nu=0.2$, a mean value often used for the concrete Poisson's coefficient in ancient monuments, see e.g. [Perucchio and Brune, 2009].

About the other material parameters, the question was more delicate. First of all, it is worth noting that experimental tests show that the tensile behavior of Roman concrete follows that of mortar (see [Samuelli-Ferretti, 1997, Giavarini et al., 2006, Jackson et al., 2009]). It has to be noted that in experiments the cracks propagate either in the mortar volume itself, in the aggregates, or at the interfacial adhesive zones [Brune, 2010]. Therefore, it seems that the contrast of the tensile strength between the Roman concrete's aggregates and the mortar it self is rather low [Jackson et al., 2009], giving a less heterogeneous material that behaves more as a mortar and less as a concrete, at least in the traction regime, which is of interest here. Being aware of this, Brune, in his $\mathrm{PhD}$ thesis [Brune, 2010], conducted experimetal tests on a reproduction of ancient mortar with different uring time, see Fig. 6.

Brune introduces a bilinear approximation of the experimental softening curve as shown in Fig. 7. Following his assumption and referring to Fig. 8, we can compute the fracture energy for normal tensile stresses as

$$
G_{f}=G_{f}^{1}+G_{f}^{2}=\int_{0}^{w_{k}} \sigma d w+\int_{w_{k}}^{w_{f}} \sigma d w
$$

where $\sigma$ is the maximum principal stress; $w$ is the displacement normal to the crack surface; $w_{k}$ is the normal displacement relative to the kink point, with stress $\sigma_{k}$; and $w_{f}$ the one corresponding to the complete loss of strength. Applying the bilinear approximation 


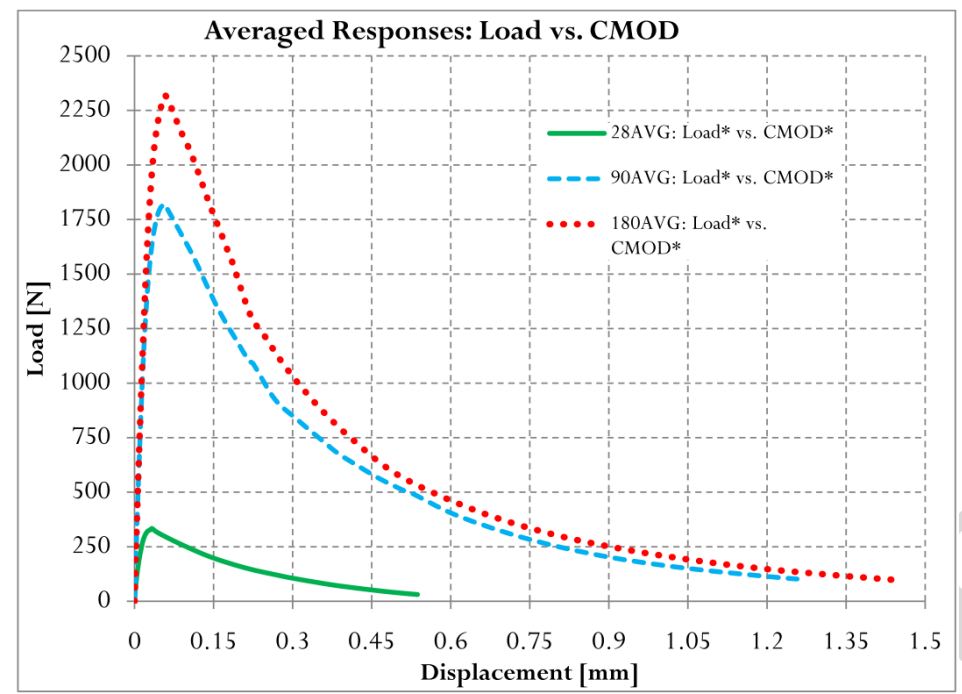

Figure 6: Average characteristic response for different curing times, according to [Brune, 2010].

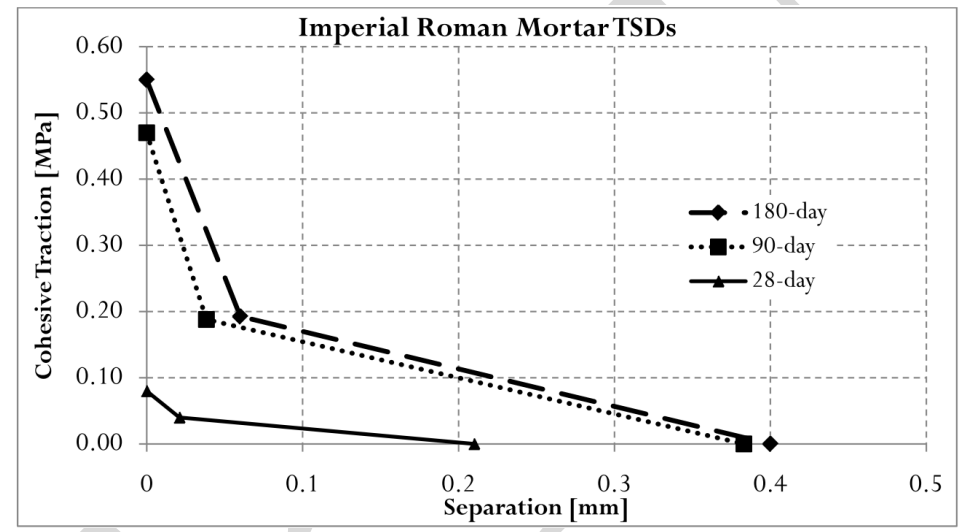

Figure 7: Best-fit traction-separation descriptions for each curing duration, according to [Brune, 2010].

of [Brune, 2010] in terms of the following parameters,

$$
\Psi=\frac{\sigma_{k}}{f_{t}}, \quad \zeta=\frac{w_{k}}{w_{f}},
$$

the two integrals in eq. (2) become

$$
\begin{aligned}
& G_{f}^{1}=\int_{0}^{w_{k}} \sigma d w=\frac{f_{t}}{2} \zeta(1+\Psi) w_{f}, \\
& G_{f}^{2}=\int_{w_{k}}^{w_{f}} \sigma d w=\frac{f_{t}}{2} \Psi(1-\zeta) w_{f},
\end{aligned}
$$

so that

$$
G_{f}=\frac{f_{t}}{2}(\zeta+\Psi) w_{f}
$$

This expression allows to compute $w_{f}$ if $G_{f}, f_{t}, \Psi$ and $\zeta$ are known:

$$
w_{f}=\frac{2}{\Psi+\zeta} \frac{G_{f}}{f_{t}} .
$$




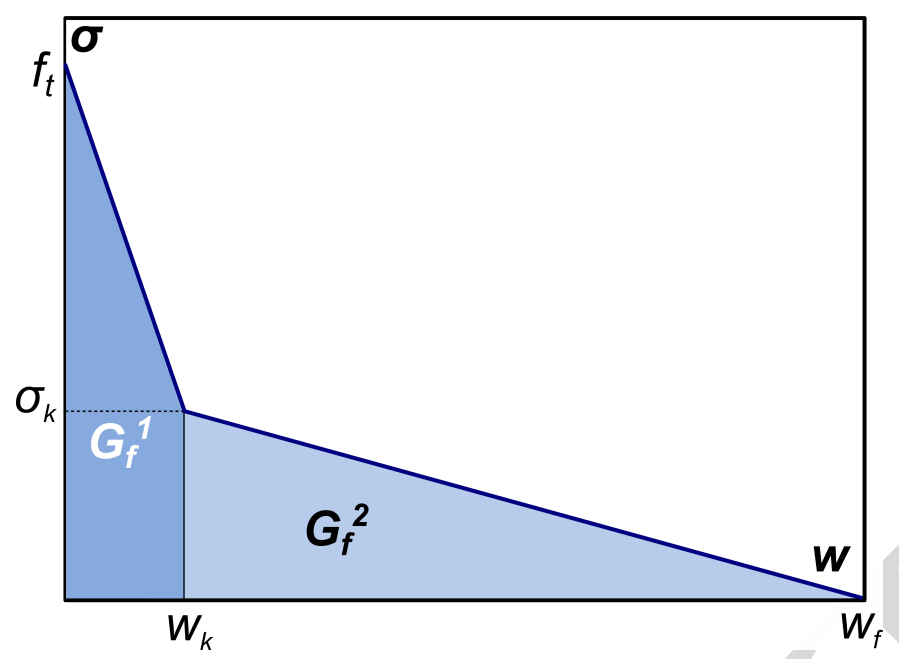

Figure 8: Traction-separation diagram and fracture energy.

Brune [2010] has proposed a series of values of $E, f_{t}, G_{f}, \Psi$ and $\zeta$ for ancient Roman mortars. Such data are given as function of curing time, and they are reported in Tab. 2. Of course, the interesting values for the present analysis are those referring to a set of 180 days.

Table 2: Roman mortar properties as function of the curing time (after [Brune, 2010]).

\begin{tabular}{cccccc}
\hline $\begin{array}{c}\text { Set } \\
{[\text { Days }]}\end{array}$ & $\begin{array}{c}E \\
{[\mathrm{GPa}]}\end{array}$ & $\begin{array}{c}f_{t} \\
{[\mathrm{MPa}]}\end{array}$ & $\begin{array}{c}G_{f} \\
{\left[\mathrm{~J} / \mathrm{m}^{2}\right]}\end{array}$ & $\Psi$ & $\zeta$ \\
\hline 28 & 1.00 & 0.08 & 5 & 0.50 & 0.10 \\
90 & 2.90 & 0.47 & 45 & 0.40 & 0.10 \\
180 & 3.37 & 0.55 & 55 & 0.35 & 0.15 \\
\hline
\end{tabular}

Regarding the Young's modulus, after comparing the value of $E$ given by Brune with other tests, see e.g. [Jackson et al., 2009], [Jackson et al., 2014], [Brune et al., 2010], [Samuelli-Ferretti, 1996], it is likely to consider the value $E=3.37 \mathrm{GPa}$, more or less, as that of a concrete whose density is $1520 \mathrm{~kg} / \mathrm{m}^{3}$.

Another value that can be extrapolated from the literature, is that concerning $E$ for the cylindrical wall; it is composed by concrete and masonry and we have found a reliable value for ancient masonry in [Como, 2013]: $E=6.6 \mathrm{GPa}$. Consequently, rounding the above values, we have put $E=3 \mathrm{GPa}$ for concrete 5 , the lightest one, and $E=7 \mathrm{GPa}$ for concrete 2. The other values can be determined upon a rule stating the dependence of $E$ on $\rho$. We did not find it in the literature about ancient concretes and the scarcity of data about these materials did not allow us to extrapolate such a rule.

That is why we have considered modern technical recommandations about lightweight concretes, [ACI, 1999], [FIB, 2000]. The following law is proposed in [Sanpaolesi and Formichi, 2009] about the Young's modulus:

$$
E=22\left(\frac{f_{c}}{10}\right)^{0.3}\left(\frac{\rho}{2200}\right)^{2},
$$


with $E$ in GPa, $\rho$ in $\mathrm{kg} / \mathrm{m}^{3}$ and $f_{c}$, the mean compressive strength, in MPa. What is apparent from this relation is that $E$ is a quadratic function of $\rho$. We have hence looked for a law representing $E$ satisfying this rule, giving a minimum of $E$ for $\rho=1350 \mathrm{~kg} / \mathrm{m}^{3}$ and the two values given above for concrete 5 and concrete 2. Some simple passages give the relation

$$
E=2.5 \times 10^{-5} \rho^{2}-0.0675 \rho+48.5625,
$$

with $E$ in GPa and $\rho$ in $\mathrm{kg} / \mathrm{m}^{3}$. This allows to have an estimation of $E$ also for the other concretes.

About the tension strength $f_{t}$, the only reliable datum is that of Brune, see Tab. 2: $f_{t}=0.55 \mathrm{MPa}$. We attribute this value to concrete 5 , the lightest one. Like for $E$, we need hence to put in relation $f_{t}$ with $\rho$. We still use a relationship proposed for modern lightweight concrete, [Sanpaolesi and Formichi, 2009]:

$$
f_{t}=0.3 f_{c k}^{2 / 3}\left(0.4+0.6 \frac{\rho}{2200}\right)
$$

where $f_{c k}$ is the characteristic value of the statistical distribution of $f_{c}$. It is likely that the compressive strength of the concretes in Tab. 3 do not change considerably. Then, making the assumption that $f_{c k}$ is practically constant, we get the following relation between the values of $f_{t}$ for two different concretes:

$$
\frac{f_{t 1}}{f_{t 2}}=\frac{0.4+0.6 \frac{\rho_{1}}{2200}}{0.4+0.6 \frac{\rho_{2}}{2200}}
$$

Then, putting $f_{t 1}=0.55 \mathrm{MPa}$ and $\rho_{1}=1350 \mathrm{~kg} / \mathrm{m}^{3}$, we get the following linear relation for $f_{t}$ as function of $\rho$ :

$$
f_{t}=3.25 \times 10^{-4}(880+0.6 \rho)
$$

with $f_{t}$ in MPa and $\rho$ in $\mathrm{kg} / \mathrm{m}^{3}$. This relation allows us to have an estimation of $f_{t}$ also for the other concretes of the Rotonda.

Concerning the fracture energy $G_{f}$, once more we have attributed the value of $55 \mathrm{~J} / \mathrm{m}^{2}$ of Tab. 2 to concrete 5. The data concerning $G_{f}$ in the literature are even more questionable than those of the other material parameters: they are considerably affected by the experimental or numerical procedure used for its evaluation besides the intrinsic properties of the material, like the size of the aggregates, the curing process among others. As a consequence, the spread of data is considerable, see for instance [Hillerborg, 1985], [Weerheijm and Vegt, 2010]. Hence, once more we have looked for a relation between $G_{f}$ and another known material parameter of concrete.

In [Dehn, 2004] the author gives a linear relation between $G_{f}$ and the tensile strength $f_{t}$ for lightweight concretes with natural sand, which is the case of the concretes of the Rotonda:

$$
G_{f}=24+16 f_{t}
$$

with $G_{f}$ in $\mathrm{J} / \mathrm{m}^{2}$ and $f_{t}$ in MPa. Assuming a linear relation between $G_{f}$ and $f_{t}$ is a strong assumption, however is justified by [Dehn, 2004] and it is frequently the case in 
geomaterials such mortars and masonry structures [van der Pluijm, 1999]. Therefore, for two different concretes, we get

$$
\frac{G_{f 1}-24}{G_{f 2}-24}=\frac{f_{t 1}}{f_{t 2}}
$$

and putting, as indicated above, $G_{f 1}=55 \mathrm{~J} / \mathrm{m}^{2}$ and $f_{t 1}=0.55 \mathrm{MPa}$, data relative to concrete 5 in Tab. 3, we get the linear relation

$$
G_{f}=24+56.36 f_{t}
$$

allowing us to obtain an estimation of $G_{f}$ for all the other concretes.

For what concerns the ratios $\Psi$ and $\zeta$ we have put $\Psi=0.35$ and $\zeta=0.15$, as suggested by Brune, see Tab. 2.

For the granite of the columns, we have taken the values found in [Buyukozturk, 1993] and we have put $\Psi=0.25$ and $\zeta=0.50$.

Using eqs. (3) and (6), we get also all the other parameters defining the tensile softening represented in Fig. 8. All the material parameters so found are shown in Tab. 3.

Table 3: Materials data

\begin{tabular}{llcccccccccc}
\hline Material & Part & $\begin{array}{c}\rho \\
{\left[\mathrm{kg} / \mathrm{m}^{3}\right]}\end{array}$ & $\begin{array}{c}E \\
{[\mathrm{GPa}]}\end{array}$ & $\nu$ & $\begin{array}{c}G_{f} \\
{\left[\mathrm{~J} / \mathrm{m}^{2}\right]}\end{array}$ & $\begin{array}{c}f_{t} \\
{[\mathrm{MPa}]}\end{array}$ & $\Psi$ & $\zeta$ & $\begin{array}{c}\sigma_{k} \\
{[\mathrm{MPa}]}\end{array}$ & $\begin{array}{c}w_{k} \\
{[\mathrm{~mm}]}\end{array}$ & $\begin{array}{c}w_{f} \\
{[\mathrm{~mm}]}\end{array}$ \\
\hline Granite & Columns & 2500 & 55.3 & 0.16 & 17.5 & 3.50 & 0.25 & 0.50 & 0.875 & 0.007 & 0.013 \\
Concrete 1 & Foundations & 2000 & 13.5 & 0.20 & 62.1 & 0.68 & 0.35 & 0.15 & 0.238 & 0.055 & 0.365 \\
Concrete 2 & Cylindrical wall & 1750 & 7.0 & 0.20 & 59.4 & 0.63 & 0.35 & 0.15 & 0.221 & 0.057 & 0.377 \\
Concrete 3 & Lower dome & 1600 & 4.6 & 0.20 & 57.7 & 0.60 & 0.35 & 0.15 & 0.210 & 0.058 & 0.385 \\
Concrete 4 & Intermidiate dome & 1500 & 3.6 & 0.20 & 56.6 & 0.58 & 0.35 & 0.15 & 0.203 & 0.059 & 0.390 \\
Concrete 5 & Upper dome & 1350 & 3.0 & 0.20 & 55.0 & 0.55 & 0.35 & 0.15 & 0.193 & 0.060 & 0.400 \\
\hline
\end{tabular}

In Fig. 9 we show the diagrams of the constitutive law $\sigma-w$. The diagram of the granite has been reduced by a factor 4 , for graphical reasons.

It is worth noting that the values of the different material parameters are close to experimental data for ancient Roman concretes, see [Lamprecht, 1984], [Jackson et al., 2009], [Brune, 2010], [Brune et al., 2010] and [Jackson et al., 2014]. They represent hence a plausible variation of such parameters with the concrete density.

\subsection{The brittle cracking model}

The nonlinear brittle cracking model proposed in [Hillerborg et al., 1976] is implemented in Abaqus using a smeared cracked approach, [ABAQUS, 2016]. According to the model, when the maximum principal stress at a Gauss point reaches the material tensile strength $f_{t}$, a fictitious crack is formed in the plane orthogonal to the direction of the principal tensile stress. The orientation of the planar Mode I crack in the three-dimensional space remains constant. This is, of course, a modeling assumption but a reasonable one for the material and loads considered.

Once the peak tensile stress is reached, a linear softening branch is followed based on the fracture energy $G_{f}$. This allows to minimize mesh dependency due to the softening behavior and to dissipate adequately the energy. 


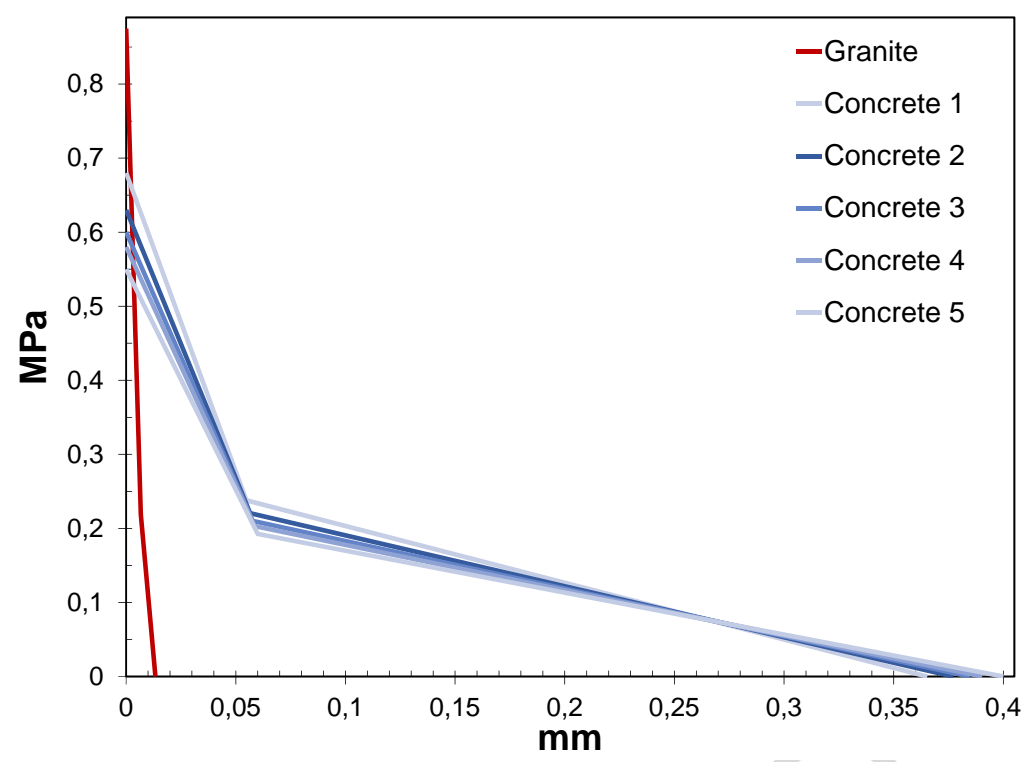

Figure 9: Traction-separation diagram of the materials composing the Pantheon.

\section{The numerical procedure}

The use of the model JWL for the blast simulation needs, as already mentioned, a meshing not only of the Pantheon's structure, but also of the air volume interested by the explosion, in this case the internal volume of the Rotonda and also a volume around the two openings, the entrance door and the oculus, the round opening at the dome's top, with a neat diameter of $\sim 7 \mathrm{~m}$, [K. de Fine Licht, 1968]. The details on the models of the air volume and of the structure and the procedure used for their numerical validation are given below, separately for the two parts. Using the symmetry of the structure, see below Fig. 14, we have modeled just one half of the structure and of the air domain. This allows, for the same computing effort, to obtain a more detailed model, i.e. a finer discretization.

\subsection{Validation of the fluid domain finite volumes model}

The model of the air domain is shown in Fig. 10. The air domain of half the structure has been decomposed into $2.068 \times 10^{6}$ 8-nodes hexahedral volume elements, for $10.34 \times$ $10^{6}$ degrees of freedom (DOF) on the whole ( 5 DOF for each volume element: the 3 displacement components and the pressure of the volume element centroid plus the the Eulerian Volume Fraction (EVF), [ABAQUS, 2016]).

In Coupled-Eulerian-Lagrangian (CEL) simulations, ABAQUS/Explicit takes into account for the Eulerian fluid domain through the so-called volume-of-fluid method: the material flowing through the mesh is tracked by the definition of an additional variable within each element, the EVF. In our case, this allows to compute not only the propagation of the shock waves, but also the diffusion of the explosive material inside the air domain. The coupling between the Lagrangian (solid) domain and the Eulerian (fluid) one, i.e. the fluid-structure interaction, is achieved by a general contact algorithm, with a null interface friction coefficient and a penalty method, [ABAQUS, 2016]. 
Ground and planes of symmetry are modeled as reflecting planes to prevent flow of material through them. The ending transversal surfaces are modeled as transmitting planes, i.e. boundary surfaces whereupon the gradients of velocity and stress are put to zero. This approach is used to simulate a far field solution at the boundary, it is only exact for outflow velocities higher than the speed of sound and is an approximation for lower velocities.

We have modeled an Eulerian domain as deep as 5 meters above the oculus and a volume of 2 meters of air on the lateral sides (see Fig. 10).
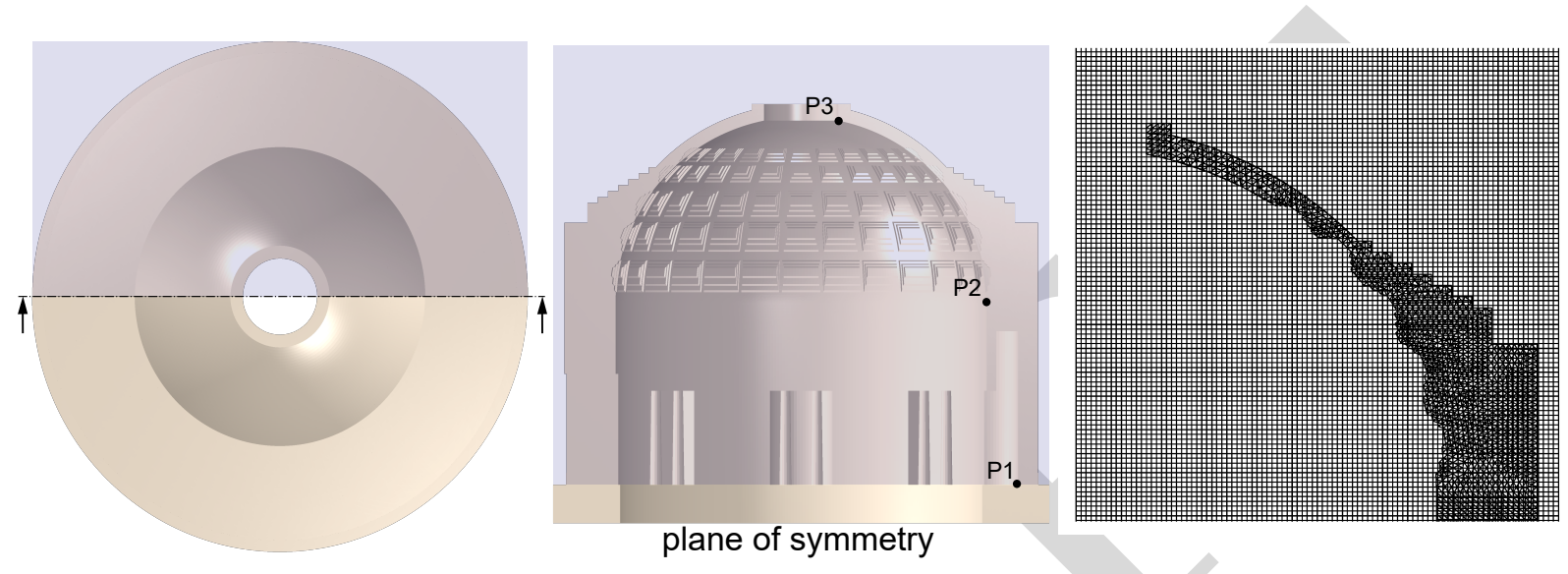

Figure 10: The air domain: overall view and location of the observation points P1 to P3 (left) and detail of the mesh (right).

The choice of the fineness of the mesh has been done upon a convergence analysis: four different meshes for the air domain have been considered: M1, with $1.48 \times 10^{6}$ DOF, M2 with $6.3 \times 10^{6} \mathrm{DOF}, \mathrm{M} 3$, the chosen mesh detailed above, and a reference mesh M4, the finest one, with $16.94 \times 10^{6}$ DOF.

For each mesh, we have computed the blast overpressure due to a TNT equivalent charge of $30 \mathrm{~kg}$ in correspondence of three different observation points: P1, P2 and P3, indicated in Fig. 10, respectively close to the base of the cylindrical wall, to its top and to the oculus. The time histories of the overpressure, for the three different points and for each mesh, are plotted in Fig. 11. 

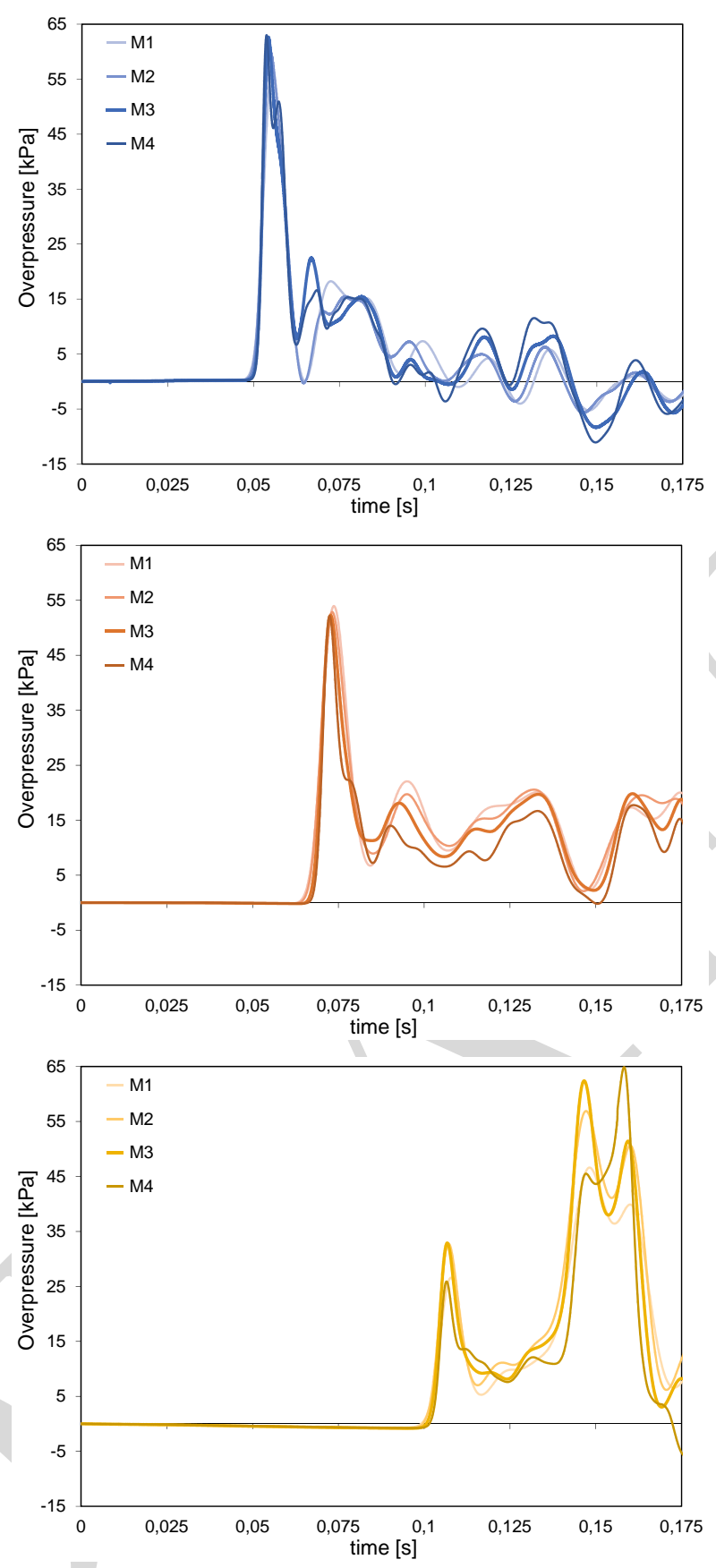

Figure 11: Time history of the overpressure for points P1 to P3 (from top to bottom).

In Fig. 12 we show, for points P1 to P3, the relative error evaluated for meshes M1 to M3 with respect to mesh M4; such an error, in percent, is computed as

$$
e r r=100\left|\frac{p_{M i}-p_{M 4}}{p_{M 4}}\right|,
$$

where $p_{M i}$ is the peak of the overpressure, in $\mathrm{P} 1, \mathrm{P} 2$ or $\mathrm{P} 3$, evaluated for mesh Mi, while $p_{M 4}$ is the same for the reference mesh M4.

Considering the results shown in Fig. 11 and 12, we can see that the choice of the mesh M3 is a fair compromise: it guarantees a good quality of the result (the maximum relative 


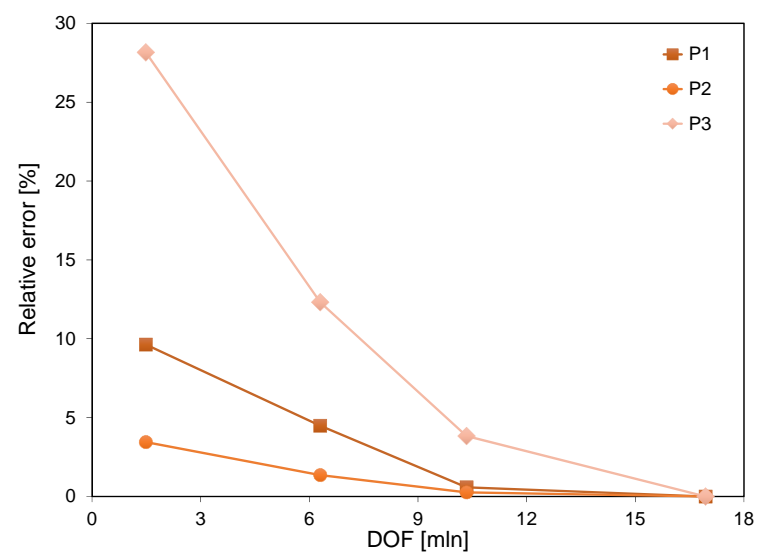

Figure 12: Relative error, eq. (15), for points P1 to P3 as function of the number of DOF.

error is $3.8 \%$, for point P3) with a problem size that is not extreme.

We have also compared the results given by JWL with those given by CONWEP for the reflected pressure $P_{r}$ on the solid points corresponding to P1, P2 and P3, see Fig. 13. The comparison clearly shows how much the use of CONWEP in a case like this one can lead to erroneous results: the time history of the overpressure is completely different, mainly due to the reflected shock waves.
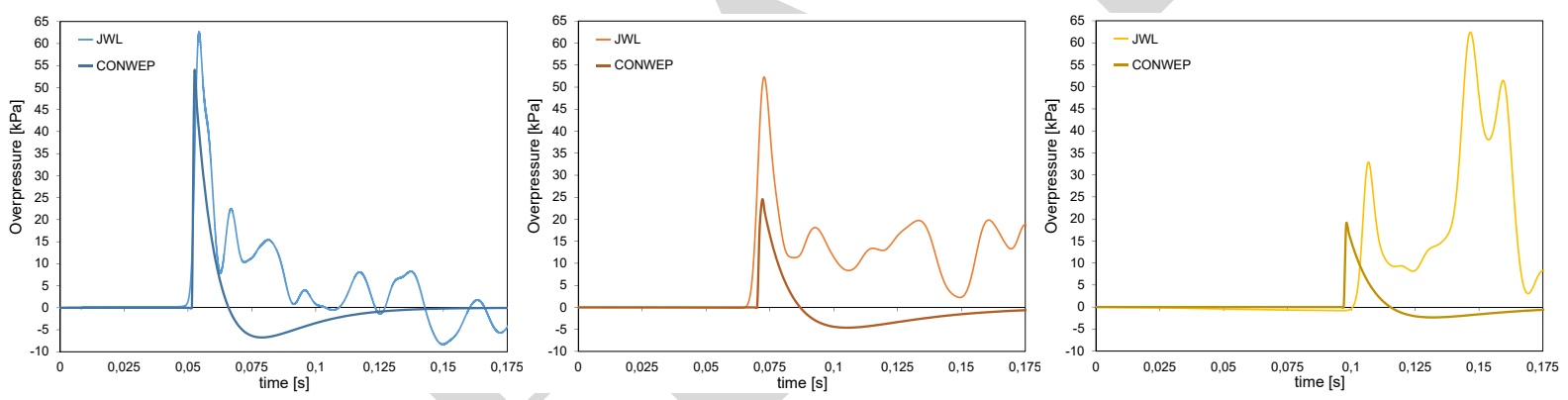

Figure 13: Comparisons of $P_{r}$ time history as evaluated by JWL and CONWEP; from the left, comparison for points P1, P2, P3.

\subsection{Validation of the Pantheon finite element model}

The entire structure of the Pantheon has been modeled using CAD programs, see Fig. 14 . The model comprehends the coffering of the dome intrados, the step-rings, the interior columns, absides and cavities present in the cylindrical wall and the foundation ring.

The CAD model has been successively meshed to obtain a finite element (FE) model. The FE model comprehends only the Rotonda, because the structural role of the pronaos is undoubtedly little, for the blast actions of an explosion in the interior of the Pantheon; so, we have neglected it.

Just like for the mesh of the air domain, we have performed a convergence analysis for validating the choice of the Rotonda mesh, composed of four-nodes tetrahedral elements, supported by both the standard and explicit solvers of ABAQUS. 

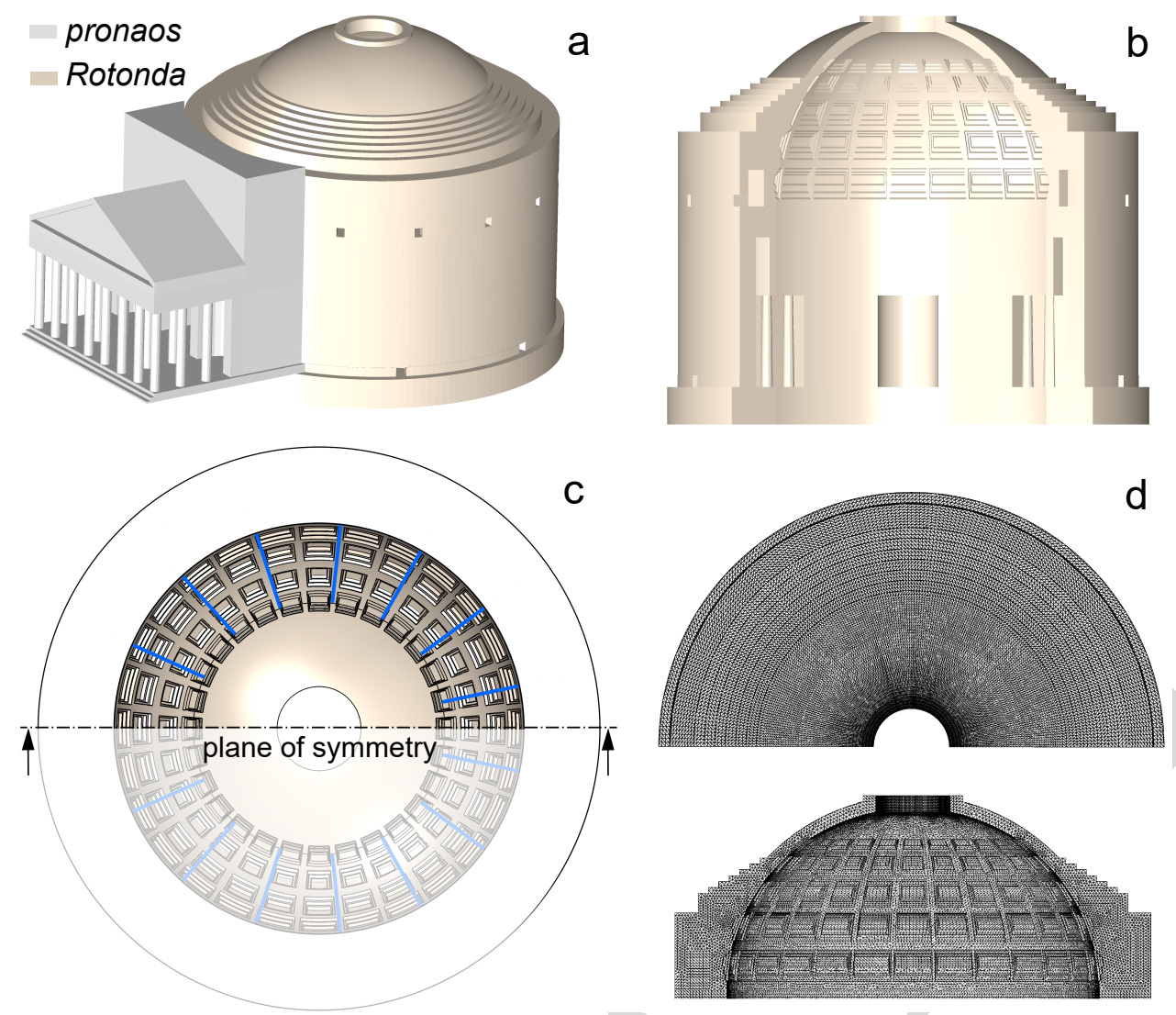

Figure 14: The model of the Pantheon; a) overall view, b) interior view of the Rotonda, c) detail of the dome with indicated the meridional cracks inserted in the model, and d) details of the structural mesh MS11.

Also in this case, the fineness of the mesh has been chosen after a convergence analysis, performed in order to obtain a reliable degree of accuracy with an acceptable size of the whole numerical model (air domain plus structure).

The convergence analysis has been done using the standard (implicit) scheme for eleven different structural meshes MSi, $\mathrm{i}=1, \ldots, 11$, whose characteristics are given in Tab. 4 .

Table 4: Characteristics of the studied structural meshes.

\begin{tabular}{lccccccccccc}
\hline Mesh & MS1 & MS2 & MS3 & MS4 & MS5 & MS6 & MS7 & MS8 & MS9 & MS10 & MS11 \\
\hline Number of DOF $\left[10^{6}\right]$ & 0.074 & 0.094 & 0.118 & 0.160 & 0.240 & 0.390 & 0.750 & 0.960 & 1.20 & 2.06 & 2.80 \\
\hline
\end{tabular}

The standard analysis made for each mesh MSi is divided into two parts: a modal analysis and a static one, for the only gravity load. We have monitored the eigenfrequencies of the first twenty vibration modes of the structure and, for the static analysis, the vertical displacement of point P3 in Fig. 11. The twenty eigenfrequencies $f_{j}, j=1,2, \ldots, 20$, and the vertical displacement $u$ of the point P3, are calculated for each structural mesh MS. The convergence has been evaluated like for the air domain, calculating for each mesh $\mathrm{MSi}=1, \ldots, 10$ the errors $\Delta f_{j}$ of the frequencies $f_{j}$ and $\Delta u$ of the displacement $u$, relatively to the same quantities $f_{j}^{r}$ and $u^{r}$, calculated for the reference mesh MS11, the 
finest one:

$$
\Delta f_{j}=\left|\frac{f_{j}-f_{j}^{r}}{f_{j}^{r}}\right|, \quad j=1,2, \ldots, 20, \quad \Delta u=\left|\frac{u-u^{r}}{u^{r}}\right|, \quad \forall \mathrm{MS}=1, \ldots, 10 .
$$

In Fig. 15 we show the diagrams of $\Delta f_{1}, \Delta f_{10}$ and $\Delta f_{20}$ along with $\Delta u$ as functions of the DOF number.

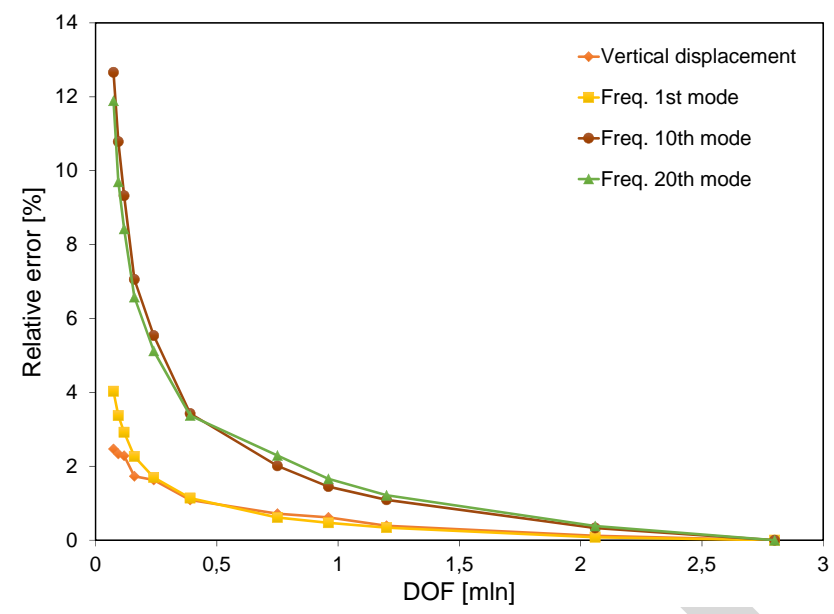

Figure 15: Relative errors $\Delta f_{1}, \Delta f_{10}, \Delta f_{20}$ and $\Delta u$ as function of the number of DOF.

Figure 16 shows the relative errors $\Delta f_{1}, \Delta f_{10}, \Delta f_{20}$ and $\Delta u$ versus the normalized CPU time necessary for th static and modal analyses; for each mesh MSi, $\mathrm{i}=1, \ldots, 11$, this is the ratio between the CPU time corresponding to MSi and that of MS1.

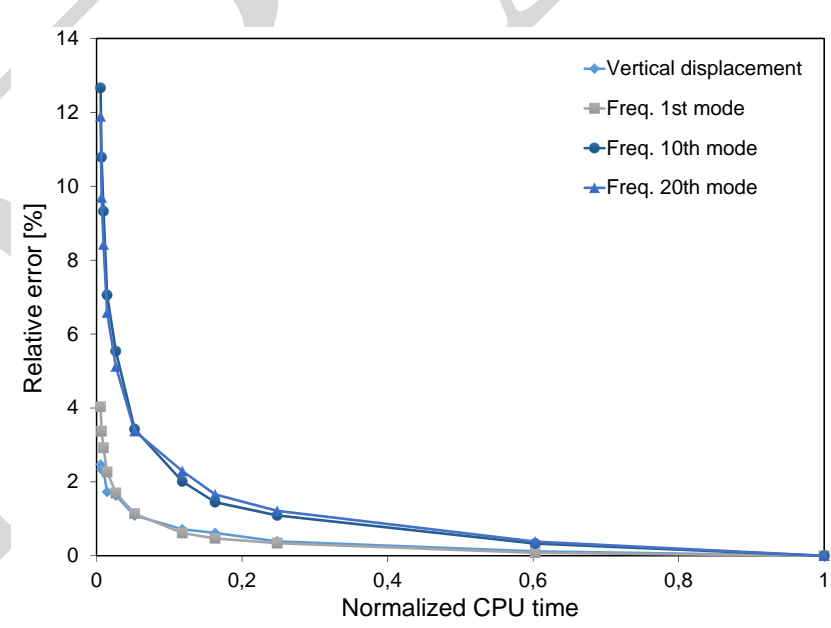

Figure 16: Relative error versus the normalized CPU time.

After evaluation of the results in Fig. 15 and 16, we have selected the mesh MS11, the finest one, for the computations. In fact, we have estimated that the convergence has been reached (the diagrams in Fig. 15 and 16 show an asymptotic behavior) while the increase of the computation time can still be considered as tolerable. A detail of the structural mesh MS11 is shown in Fig. 14. 
To take into account for the existing cracks in the dome, Fig. 3, we have modeled 14 cracks, propagating along the meridians up to $57^{\circ}$ above the plane passing through the sphere center in Fig. 2; they are indicated in Fig. $14 \mathrm{c}$ ). Each crack is modeled as an interface, with a hard normal contact behavior (no penetration between interacting parts of the model) and a Coulomb friction coefficient of 0.5 (cf. [Brune and Perucchio, 2012]). A penalty algorithm was used [ABAQUS, 2016] for the tangential components of the contact stress.

Parallel computing is used to reduce significantly the duration of the analyses. All the simulations have been performed using a 24-cores workstation; the entire model is, thus, divided into 24 geometric domains, taking advantage of the 24 processors of the machine.

The energy balance of the coupled fluid-solid numerical simulation is verified by monitoring the total energy, $E_{\text {total }}$, of the whole model defined as (the superscripts $E$ and $L$ refer to the Eulerian and Lagrangian domains, respectively)

$$
E_{\text {total }}=\left(E_{i}+E_{v}+E_{k e}\right)^{E}+\left(E_{i}+E_{v}+E_{k e}\right)^{L}-E_{w}
$$

where $E_{v}$ is the viscous energy dissipated by bulk viscosity; $E_{k e}$ is the kinetic energy; $E_{w}$ is the work done by gravity load and $E_{i}$ is the internal energy, which is given by the sum of elastic strain energy $E_{e}$, artificial strain energy $E_{a}$ (that is the energy stored in hourglass resistances) and energy dissipated through damage $E_{d m d}$, namely

$$
E_{i}^{E}=E_{e}^{E}+E_{a}^{E}, \quad E_{i}^{L}=E_{e}^{L}+E_{a}^{L}+E_{d m d}^{L}
$$

for the Eulerian and Langrangian domains, respectively. The consistency of the numerical simulation is checked by computing the variation of the total energy with respect to its initial value $\left(\left.E_{\text {total }}\right|_{t=0}\right.$, when $\left.t=0\right)$ during the mechanical calculations, i.e.

$$
\Delta E_{\text {total }}(t)=\left|\frac{\left.E_{\text {total }}\right|_{t=0}-E_{\text {total }}(t)}{\left.E_{\text {total }}\right|_{t=0}}\right| .
$$

The total energy is found to be constant within an error $\Delta E_{\text {total }}<1 \%$, that is acceptable for an explicit scheme.

\section{Numerical simulations}

We have simulated the effects of an explosion in the center of the Rotonda. It is worth noting that the quantity of explosive has been selected by searching the minimum quantity of TNT able to cause the partial collapse of the structure. Figures 17 to 19 represent the pressure field at different (normalized) times in the interior of the Rotonda and, starting from the moment where the first cracks appear in the dome, the effects on the structure, where the propagation of cracks is clearly visible. We comment separately the pressure field and the effects on the structure. 


\subsection{Evolution of the pressure field}

The pressure field represented in Fig. 17 is comprehensive of all the blast phenomena: shock wave, reflected shock waves and dynamic pressure. The first two sketches in Fig. 17 show the very initial phases of the blast, with the shock wave propagating hemispherically until it touches the cylindrical wall. At this moment, the reflected shock waves add to the principal one, creating a complex pressure field and, though the principal shock wave decreases in intensity, important local concentrations of pressure are possible due to the interaction between the principal shock wave and the reflected ones.

Local concentration of the pressure are clearly visible in the interior of the niches and in the parts of the coffering looking downward, but the most important concentration happens exactly in the central axis of the Rotonda, of course as an effect of its cylindrical symmetry. An important zone of high pressure, in the form of a butterfly, forms and progresses towards the oculus. This last represents an important escape way for the pressure and the gases, as clearly visible in the last pictures of Fig. 17. Also the entrance door is an escape way, but apparently it has a least effect of the oculus, because the focalized shock waves move toward the dome's top. 

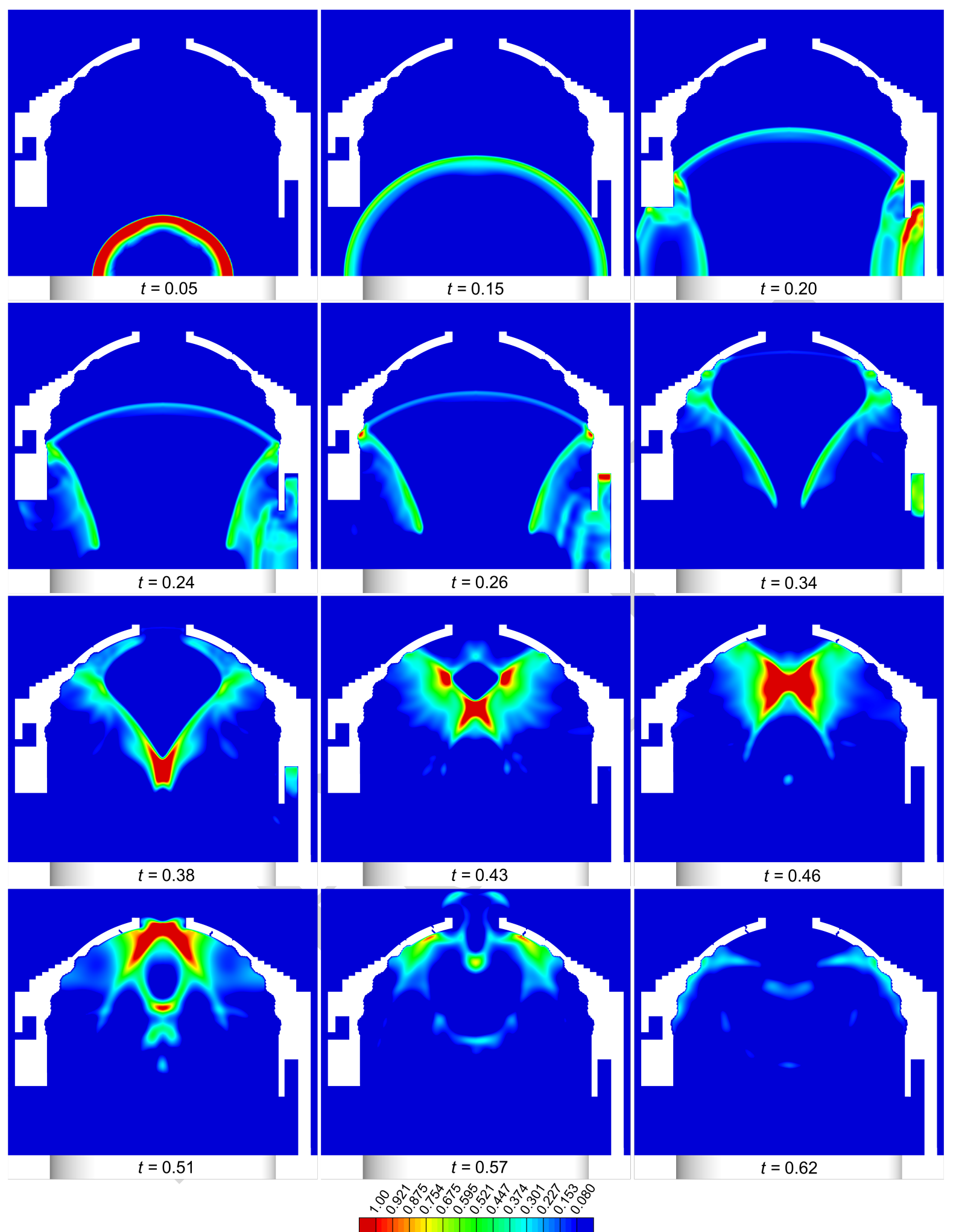

Figure 17: The evolution of the (normalized) overpressure field inside the Rotonda. Dark blue regions represent negative or zero overpressure.

Such pressure concentrations can lead to local value of the overpressure far greater than that produced by the original shock wave. This is clearly visible, e.g., in Fig. 11, where 
the pressure for point P3, close to the oculus, clearly shows secondary peaks far higher than the first one, due to the impinging shock wave. These secondary peaks mark the passage, through the oculus, of the "butterfly" pressure wave. Another important fact, still visible in Fig. 11, is the fact that the overpressure lasts much more than the single original shock wave. Of course, this has a strong effect on the damage of the structure, because it is much longer exposed to high impact pressures.

Rather interesting is the fact that the coffers act like dampers of the pressure impulse. The sharp-cornered surfaces of the coffers are nothing but obstacles to the propagation of the internal blast wave: the waves reflected by the coffering array looking downward contrast the rising incident wave through the particular combination of incident and reflection angles, as clearly shown in Fig. 17. The arrangement of the coffers themselves results in a step-by-step attenuation, mitigating the incident pressure as getting closer to the upper part of the dome and the intense, butterfly-shaped, concentration that rises in the center of the Rotonda.

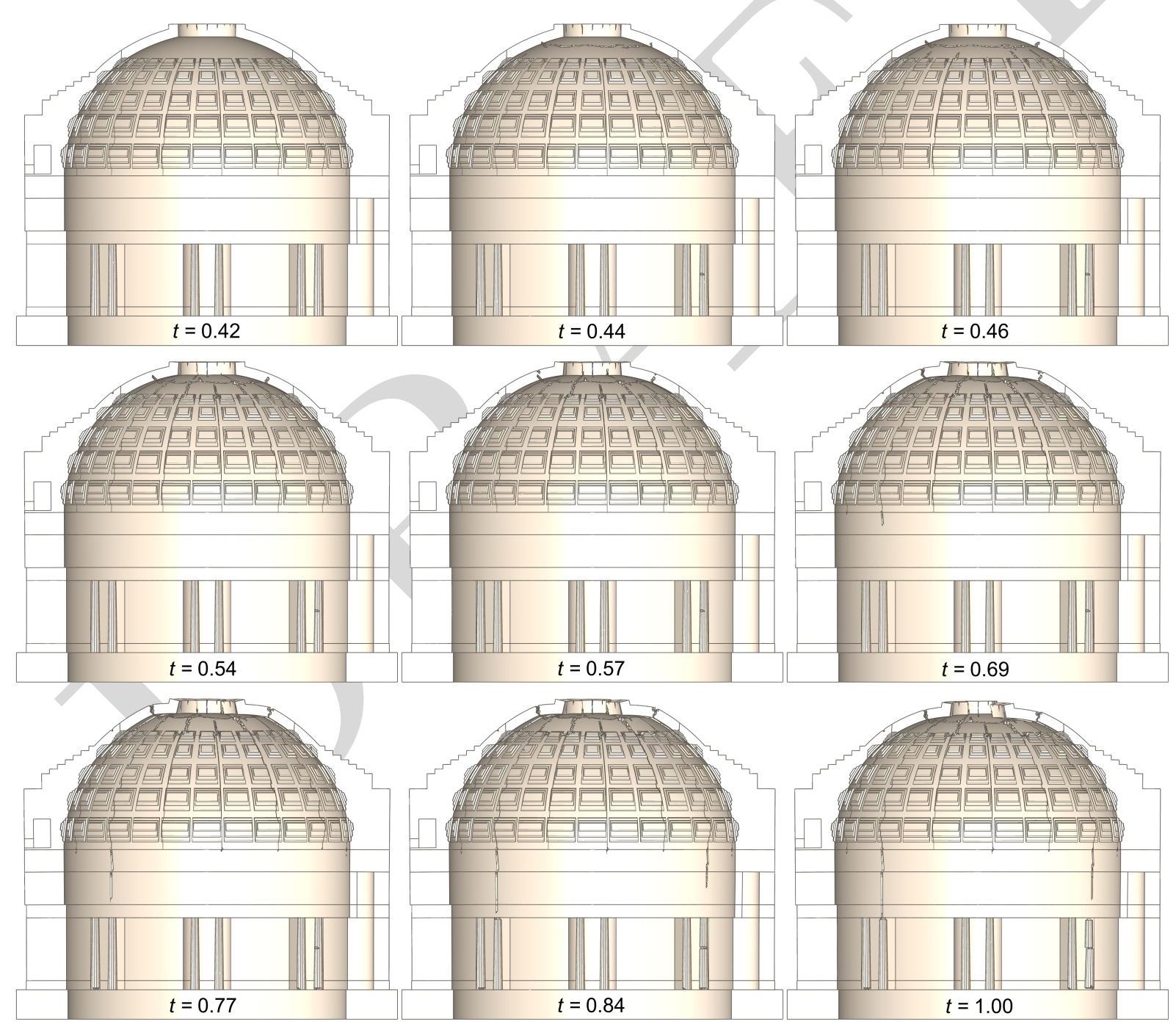

Figure 18: The evolution of the structural damage of the Rotonda. 


\subsection{Evolution of the structural damage}

It is exactly the "butterfly" zone of focalized pressure, result of the interaction of the principal and reflected shock waves, that produces the principal damages to the Rotonda, and in particular it is likely to produce the destruction of the dome.

This is apparent looking at Fig. 18: the first cracks appear in the compression ring of the oculus when the focalized pressure approaches the dome and when it passes through the oculus, the existing cracks begin to propagate toward the dome's top and eventually they reach it. The static regime of the dome is completely changed, because a shell behavior is no more possible and, each part of the dome behaving like a wedged cantilever, a circular crack appears in the upper part of the dome as a consequence of the bending tensile stresses produced by gravity so that, in the end, the upper part of the dome collapses.

In the same time, in the the cylindrical wall the existing cracks propagate through the entire wall thickness, as depicted in Figs. 18 and 19. Moreover it is shown that the granite columns are fractured by the blast.

It is worth mentioning that tension is the main damage mechanism. The developped compressive stresses are much lower than the typical compressive strength of the material involved, even under blast actions. This is discussed further in the Appendix.

The failure and collapse of the dome is hence the consequence of different causes: the blast, the propagation of the existing cracks and the selfweight of the dome.

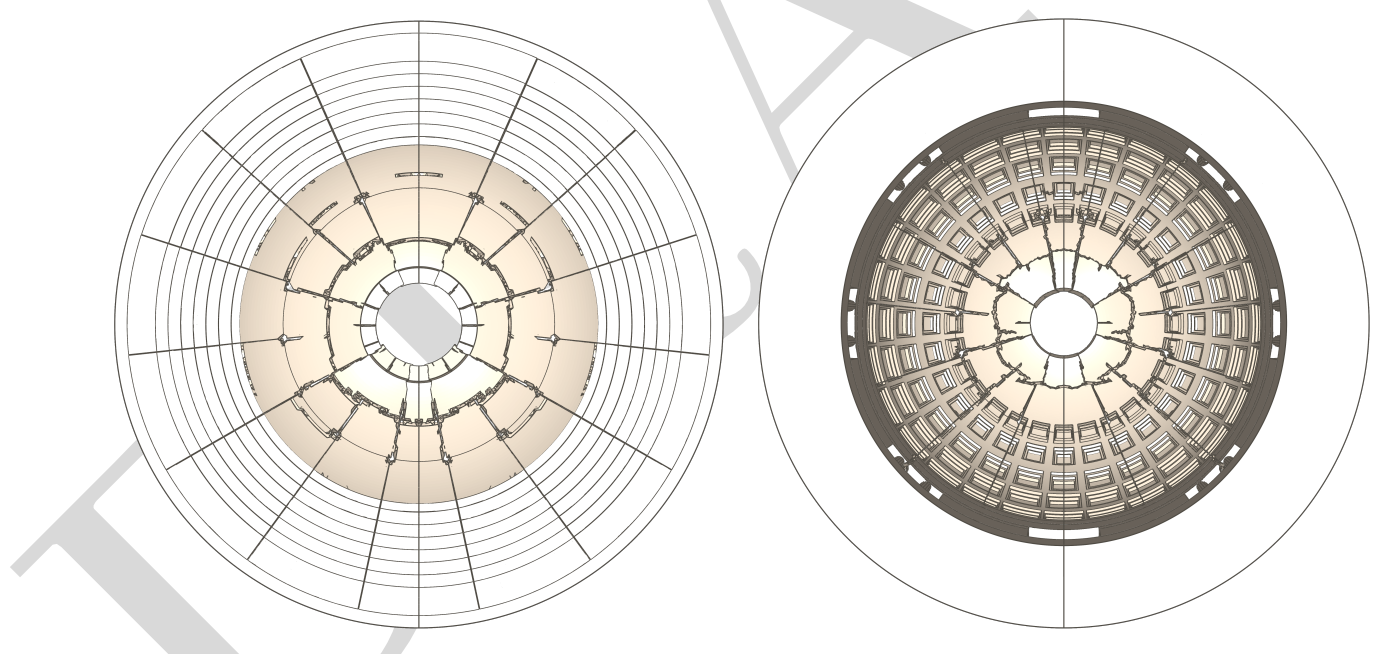

Figure 19: Structural damage of the dome at the end of the calculations: external (left) and internal (right) views.

The real extent of the existing cracks in the Rotonda's dome is uncertain. Therefore, for the sake of completeness, we performed the same simulation described above and on exactly the same model of the Pantheon without the existing cracks. All the other parameters were left unchanged.

The evolution of the structural damage of the structure in this case is depicted in Fig.s 20 and 21. It is evident that the case without cracks has a different failure mechanism, i.e. the upper part of the dome is damaged, but to a smaller extent with respect to the case with cracks. 


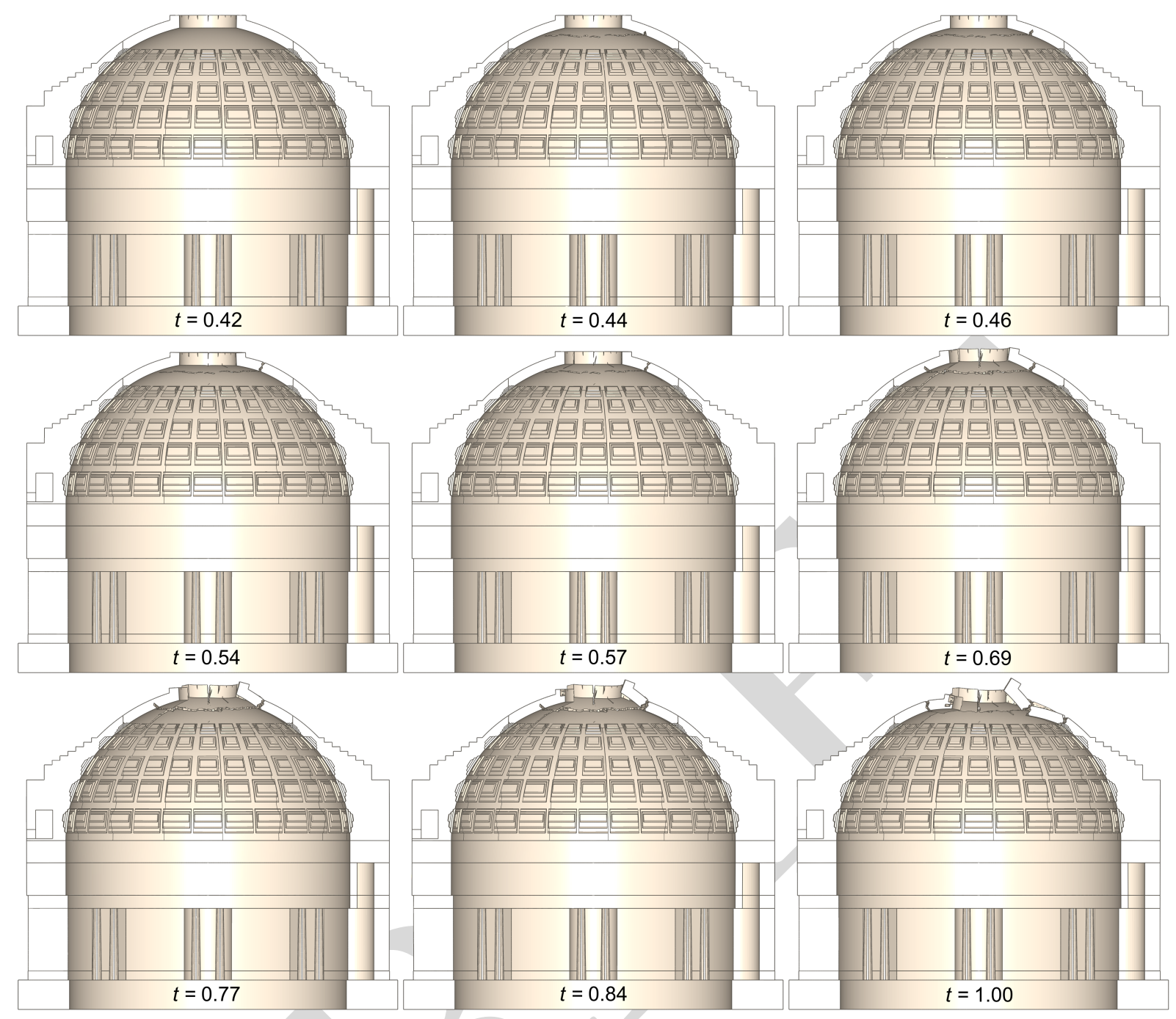

Figure 20: The evolution of the structural damage of the Rotonda, without pre-existent cracks.

This is because in the case of the cracks, as mentioned above, the blast effect is a propagation of these toward the top of the dome and the creation of the cantilever effect, that destroy a large part of the dome under the action of the gravity. In the case without cracks, the upper part of the dome is destroyed mainly by the cracks produced at the intrados by the blown of the blast. Moreover, while in the case with cracks these propagates also downward in the cylindrical wall of the Rotonda, this last is practically unaffected by the explosion. As a conclusion, we can say that also if the existing cracks are ignored in the simulation, the dome is destroyed by the blast, though to a less extent, while the cylindrical wall remains intact (see Fig. 22). The existing cracks constitute hence a weakness of the whole structure of the Pantheon for what concerns the effects of an explosion. 

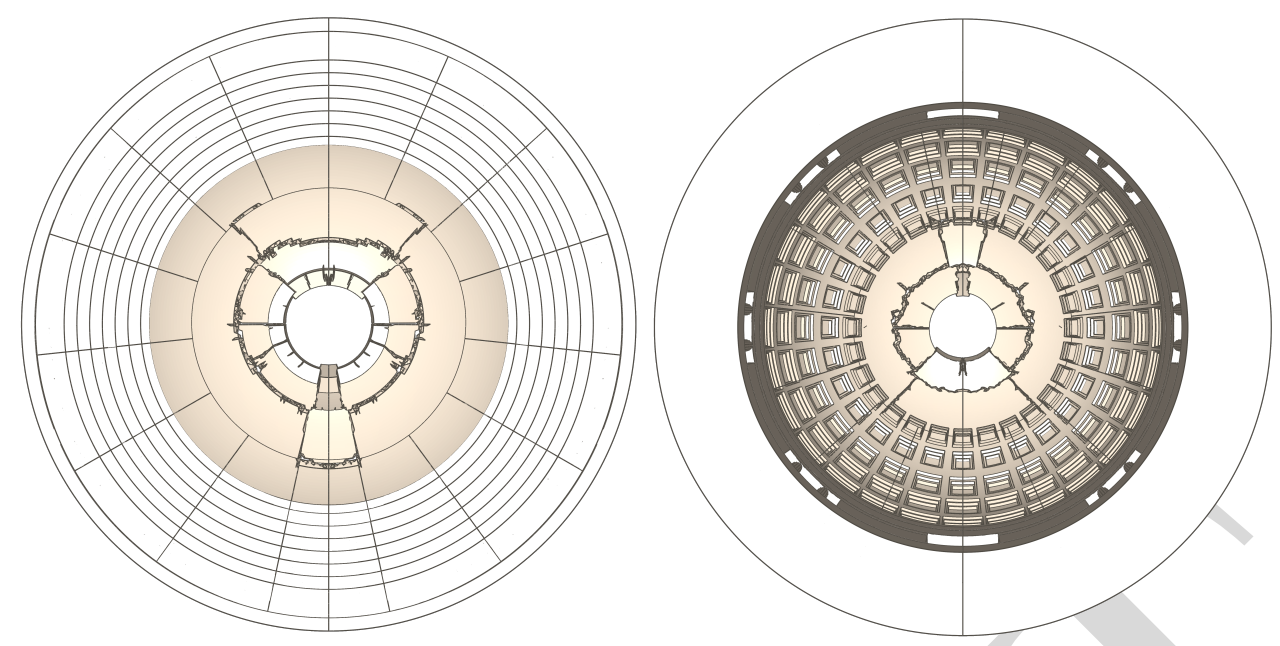

Figure 21: Structural damage of the dome at the end of the calculations: external (left) and internal (right) views, without pre-existent cracks.
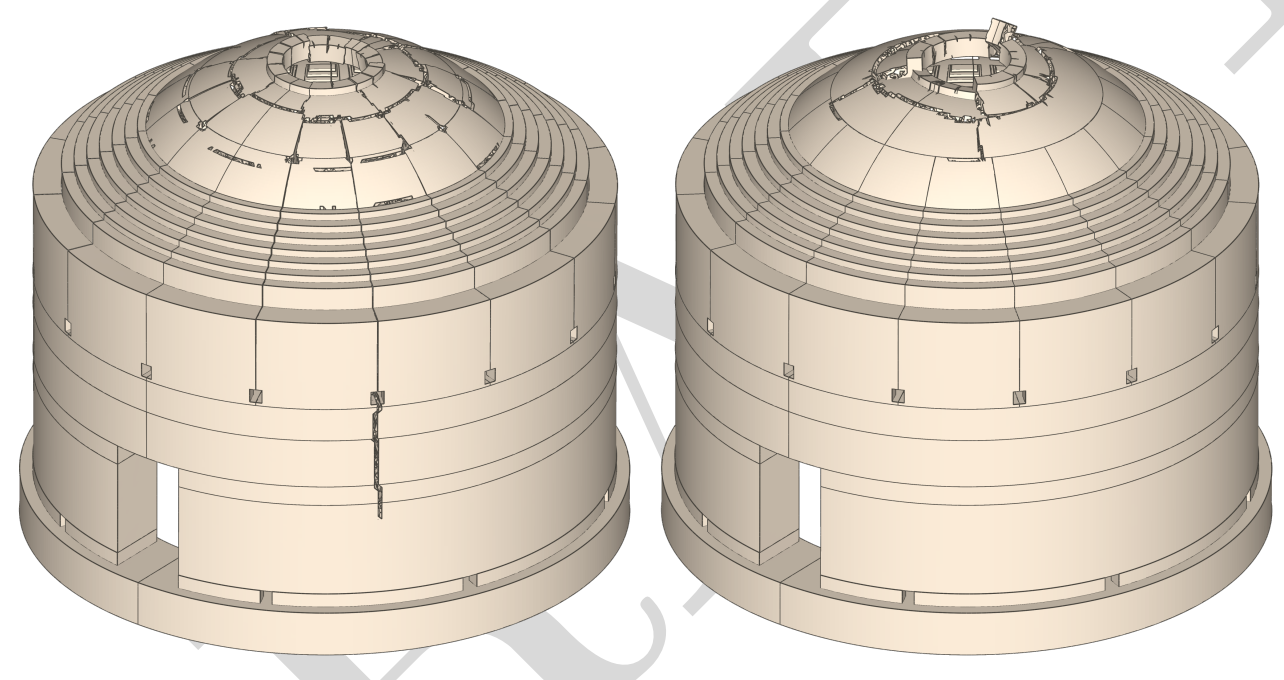

Figure 22: Comparison of the structural damage of the dome at the end of the calculations: with pre-existent cracks (left) and without (right).

\subsection{Considerations about the numerical simulations}

The results presented hereon have been produced by a numerical simulation; though there is always, in such a kind of problems, a certain ineradicable difference between reality and simulation, nevertheless they certainly grasp the main response of the structure to a blast.

For what concerns the simulation of the blast itself, it clearly shows how much it is important to take into account for reflected shock waves, a fundamental aspect of the phenomenon for internal explosions. This means that a study of such phenomena done using empirical models like CONWEP, not taking into account for reflected shock waves, can lead to results really far from reality and principally underestimate the effects of the blast on the structure.

The response of the structure deserves a commentary. The results shown hereon have been 
obtained for the least quantity of explosive able to destroy, at least in part, the Pantheon. Without entering in detail, it is thought that bringing such a quantity of explosive in the interior of the monument would be impossible, if not with some mechanical means.

In other words, the Pantheon is intrinsically safe with respect to explosions. This is due to different reasons. On one hand, its dimensions: it is a large building and the structure itself is really massive: the cylindrical wall thickness varies from $\sim 2.4 \mathrm{~m}$ to $\sim 6 \mathrm{~m}$, while that of the dome of $\sim 1.5 \mathrm{~m}$ at its top, as already mentioned. Then, its form: the cylindrical form is by itself more likely to resist to impact pressures than a flat one, more exposed to bending stresses. Finally, and this point is really surprising, the material. As already highlighted in Sec. 4.1, Roman concrete has mechanical properties quite different from modern light concretes: its Young's modulus $(\sim 3$ to $\sim 13 \mathrm{GPa}$, [Brune, 2010], [Lamprecht, 1984]), good tensile strength, $\sim 0.6 \mathrm{MPa}$, and fracture energy, $\sim 55 \div 60$ $\mathrm{J} / \mathrm{m}^{2}$, confer to Roman concrete very good properties of resilience and shock absorbing. Though, of course, ancient Romans did not conceive this material for absorbing a blast effects, nevertheless it reveals once more to be a key of the structural success of the Pantheon.

\section{Acknowledgments}

We wish to thank D. Gomes and I. Naciri, students of Master DSME of University of Versailles, who realized the CAD model of the Pantheon.

We are pleased to thank Dr. Arch. E. Pulvirenti for her kindness in allowing us to publish her pictures of the Pantheon.

\section{References}

ABAQUS. Abaqus analysis user's guide. Technical Report Abaqus 6.14 Documentation, Simulia Corp., 2016.

ACI. Guide for structural lightweight aggregate concrete. Technical report, America Concrete Institute, 1999.

P. Brune and R. Perucchio. Roman concrete vaulting in the great hall of trajan's markets: Structural evaluation. Journal of Architectural Engineering, 18(4):332-340, 2012.

Ph. F. Brune. The Mechanics of Imperial Roman Concrete and the Structural Design of Vaulted Monuments. PhD thesis, Department of Mechanical Engineering - University of Rochester, Rochester, NY, 2010.

Ph. F. Brune, R. Perucchio, A. R. Ingraffea, and M. D. Jackson. The toughness of imperial roman concrete. In B. H. Oh et al., editor, Recent advances in fracture mechanics of concrete, pages 38-45, Seoul, South Korea, 2010. Korea Concrete Institute.

O. Buyukozturk. Interface fracture and crack propagation in concrete composites. In C. Huet, editor, Micromechanics of concrete and cementitious composites, pages 203212, Lausanne, Switzerland, 1993. Presses Polytechniques et Universitaires Romandes. 
M. Como. Statics of historic masonry constructions. Springer Verlag, Berlin, Germany, 2013.

H. J. Cowan. The master builders. A history of structural and environmental design from ancient egypt to the nineteenth century. J. Wiley \& Sons, New York, NY, 1977.

F. Dehn. Fracture mechanical behaviour of lightweight aggregate concrete. In Fracture mechanics of concrete structures. Proceedings of International conference on fracture mechanics of concrete and concrete structures., Vail, Colorado, 2004.

H. Draganic and V. Sigmund. Blast loading on structures. Technical Gazette (Croatia), 19:643-652, 2012.

FIB. Lightweight aggregate concrete. Technical report, International Federation for Structural Concrete, 2000.

C. Giavarini, A. Samuelli-Ferretti, and M. L. Santarelli. Mechanical Behaviour and Properties, pages 107-120. Springer Netherlands, Dordrecht, 2006. ISBN 978-1-4020-5077-0. doi: 10.1007/978-1-4020-5077-0_7.

J. Heyman. The stone skeleton. Cambridge University Press, Cambridge, UK, 1995.

A. Hillerborg. Results of three comparative test series for determining the fracture energy $G_{f}$ of concrete. Matériaux et Constructions, 18:407-413, 1985.

A. Hillerborg, M. Modéer, and P. E. Petersson. Analysis of crack formation and crack growth in concrete by means of fracture mechanics and finite elements. Cement and Concrete Resistance, 6:773-782, 1976.

S. Ivancic, Ph. F. Brune, and R. Perucchio. A Concrete Damage Plasticity Model for Ancient Roman Pozzolanic Concrete. In Proc. of the 9th International Masonry Conference, Guimarães, Portugal, 2014.

M. D. Jackson, J. M. Logan, B. E. Scheetz, D. M. Deocampo, C. G. Cawood, F. Marra, M. Vitti, and L. Ungaro. Assessment of material characteristics of ancient concretes, Grande Aula, Markets of Trajan, Rome. Journal of Archaeological Science, 36:24812492, 2009.

M. D. Jackson, E. N. Landis, Ph. F. Brune, M. Vitti, H. Chen, Q. Li, M. Kunz, H.-R. Wenk, P. J. M. Monteiro, and A. R. Ingraffea. Mechanical resilience and cementitious processes in Imperial Roman architectural mortar. PNAS, 111:18484-18489, 2014.

H. Jones and A. R. Miller. The detonation of solid explosives. Proc. Royal Soc. A, 194: $480,1948$.

K. de Fine Licht. The Rotunda in Rome: a study of Hadrian's Pantheon. Jutland Archeological Society, Copenhagen, Denmark, 1968.

V. Karlos and G. Solomos. Calculation of Blast Loads for Application to Structural Components. Technical report, Joint Research Center of the European Commission, 2013.

C. N. Kingery and G. Bulmash. Technical report ARBRL-TR-02555: Air blast parameters from TNT spherical air burst and hemispherical burst. Technical report, U.S. Army Ballistic Research Laboratory, 1984. 
Z. Koccaz, F. Sutcu, and N. Torunbalci. Architectural and structural design for blast resistant structures. In Proc. of 14th World Conference on Earthquake Engineering, Beijing, 2008.

H. O. Lamprecht. Opus caementicium: Bautechnik der Römer. Beton-Verlag, Düsseldorf, Germany, 1984.

L. C. Lancaster. Concrete Vaulted Construction in Imperial Rome. Cambridge University Press, New York, NY, 2005.

E. Lee, M. Finger, and W. Collins. JWL equation of state coefficient for high explosives, UCID - 16189. Technical report, Lawrence Livermore National Laboratory, 1973.

E.L. Lee, H.C. Horning, and J.W. Kury. Adiabatic expansion of high explosives detonation products. Technical Report TID 4500 - UCRL 50422, Lawrence Livermore National Laboratory, 1968.

T. A. Marder and M. Wilson Jones. The Pantheon: From Antiquity to the Present. Cambridge University Press, Cambridge, UK, 2015.

R. Mark. Light, wind and structure. The MIT Press, Cambridge, Massachussets, 1990.

R. Mark and P. Hutchinson. On the Structure of the Roman Pantheon. The Art Bulletin, 68:24-34, 1986.

F. Masi. Blast actions from high explosives. Studies on their simulation and effects. $\mathrm{PhD}$ thesis, Department of Mechanical Engineering - University of Florence, Florence, 2017.

T. Ngo, P. Mendis, A. Gupta, and J. Ramsay. Blast loading and blast effects on structures - An overview. Electronic Journal of Structural Engineering, Special Issue: Loading on Structures:76-91, 2007.

R. Perucchio and Ph. F. Brune. Concrete vaulting in Imperial Rome: A structural analysis of the Great Hall of Trajan's Markets. In J. F. Abel and J. R. Cooke, editors, Proc. of the 6th International conference on Computation of Shell and Spatial Structures, Cornell University, Ithaca, NY, 2008.

R. Perucchio and Ph. F. Brune. The Evolution of Structural Design of Monumental Vaulting in Opus Caementicium in Imperial Rome. In Proceedings of the Third International Congress on Construction History, Cottbus, Germany, May 2009.

E. Pulvirenti. Didatticarte, 2014. URL http://www.didatticarte.it/Blog/?p=2169.

A. M. Remennikov. A review of methods for predicting bomb effects on buildings. $J$ of Battlefield Techn, 6:5-10, 2003.

A. Samuelli-Ferretti. Materiali da costruzione e tecnologie costruttive del patrimonio archeologico e monumentale romano con particolare riferimento al tipo laziale ed all'opus latericium. Technical report, Dipartimento di Ingegneria Strutturale e Geotecnica - University of Rome "La Sapienza", Rome, Italy, 1996.

A. Samuelli-Ferretti. Proposte per lo studio tecnico-sperimentale della statica dei monumenti in opus caementicum. Journal of Archeological Science, 36:2481-2492, 1997. 
L. Sanpaolesi and P. Formichi. Calcestruzzo leggero strutturale di argilla espansa. Leca, Parme, Italy, 2009.

I. Stefanou, K. Sab, and J.-V. Heck. Three dimensional homogenization of masonry structures with building blocks of finite strength: A closed form strength domain. International Journal of Solids and Structures, 54:258-270, 2015.

A. Terenzio. La restauration du Panthéon de Rome. In La Conservation des Monuments d'Art \& d'Histoire, pages 280-285. Office International des Musées, Paris, France, 1934.

USACE. TM 5-855-1: Design and Analysis of Hardened Structures to Conventional Weapons Effects. Technical report, U. S. Army, 1986.

USACE. TM 5-1300: Structures to Resist the Effects of Accidental Explosions. Technical report, U.S. Army, 1990.

USACE. UFC 3-340-02: Structures to Resist the Effects of Accidental Explosions. Technical report, U.S. Army, 2008.

R. van der Pluijm. Out-of-Plane bending of Masonry. Behavior and Strength. Technische Universiteit Eindhoven, 1999.

P. Vannucci, F. Masi, and I. Stefanou. A study on the simulation of blast actions on a monumental structure. International Journal of Mechanical Sciences, (submitted), 2017a. URL https://hal archives-ouvertes.fr/hal-01447783v3/document.

P. Vannucci, I. Stefanou, and F. Masi. Report of the project "Cathédrales durables". Technical report, CNRS, Paris, France, 2017b.

J. Weerheijm and I. Vegt. The dynamic fracture energy of concrete. Review of test methods and data comparison. In B. H. Oh et al., editor, Recent advances in fracture mechanics of concrete, pages 419-427, Seoul, South Korea, 2010. Korea Concrete Institute.

M. L. Wilkins. The equation of state of PBX 9404 and LX 04-01. Technical Report UCRL - 7797, Lawrence Radiation Laboratory, 1964.

M. Wilson-Jones. Principles of Roman Architecture. Yale University Press, New Haven, Connecticut, 2000.

\section{Appendix}

The assumption of a linear elastic behavior in compression needs to be validated by monitoring the compressive stresses developed under the blast action in the above simulations. Figure 23 shows the minimum principal stress over the structure during the entire calculations (computed as the minimum, over the total time duration, of the minimum principal stress at the Gauss point of each element). The maximum compressive stress appears on the granite columns and takes a value of 5.50 MPa which is two order of magnitude less than the typical ultimate granite strength, $\sim 123 \mathrm{MPa}$ (see [Buyukozturk, 1993]). As far as it concerns the other parts of the structure we observe a maximum compressive stress of 2.50 MPa. This value is smaller the assumed compressive strength of the material $(\sim 5$ $\mathrm{MPa})$. 


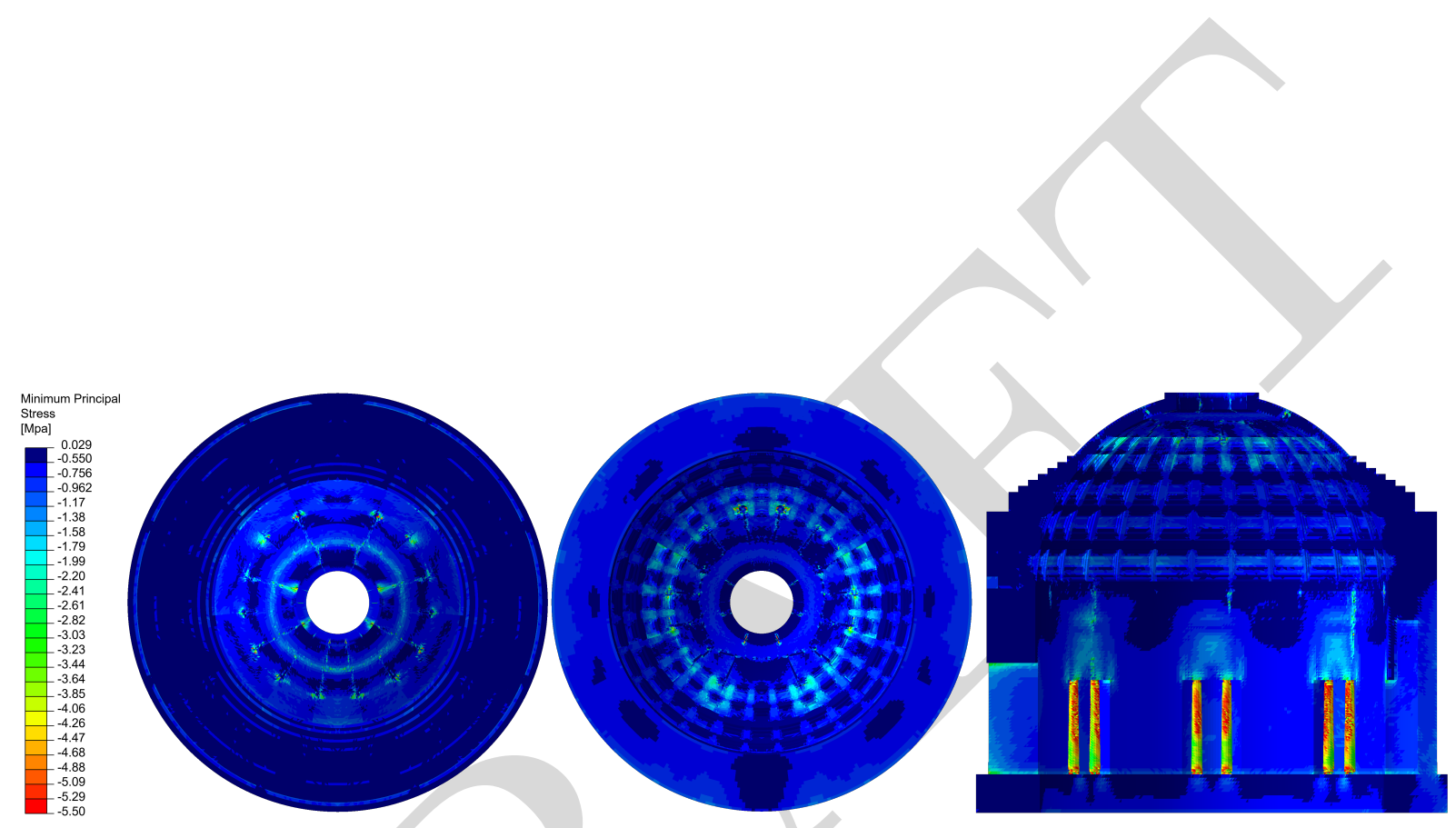

Figure 23: Minimum principal stress over the total time duration. Contours are represented by extrapolating the values at the material point of each FE to produce a single value per element's face. 